\title{
Underlying mechanism of the efficiency loss in CZTSSe solar cells: Disorder and deep defects
}

\author{
Biwen Duan ${ }^{1,3}$, Jiangjian $\mathrm{Shi}^{1}$, Dongmei $\mathrm{Li}^{1,3,4}$, Yanhong Luo ${ }^{1,3,4}$, Huijue $\mathrm{Wu}^{1}$ and Qingbo Meng ${ }^{1,2,4^{*}}$
}

\begin{abstract}
Although $\mathrm{Cu}_{2} \mathrm{ZnSn}\left(\mathrm{S}_{x}, \mathrm{Se}_{1-x}\right)_{4}$ (CZTSSe) is a promising candidate for thin-film photovoltaics, its cell performance is currently limited by the large voltage loss. Although a series of studies on the efficiency loss mechanism of CZTSSe solar cell have been carried out in the past few years, no convincing understanding has been obtained until now. In this review, the current findings regarding the underlying mechanism of the efficiency loss in CZTSSe solar cells are systematically summarized and analyzed. The properties of atomic disorder and deep defects in CZTSSe materials and their effects on device performance are discussed. The synergistic effect is proposed to help understand the defect-related charge loss in the absorber. Furthermore, the experimental methods of defect identification and defect control are presented, in an attempt to identify the killer defects that can be responsible for the ultra-short minority lifetime of CZTSSe material. By comprehensively and dialectically understanding these defect properties of the CZTSSe solar cell, we believe breakthrough in the cell efficiency will come soon with our concentrated effort.
\end{abstract}

Keywords: CZTSSe solar cell, voltage loss, disorder, defect

\section{INTRODUCTION}

Photovoltaics (PV) have been an important renewable energy to meet the increasing global energy demand, with a cumulative power installed capacity of $515 \mathrm{GW}$ [1]. The silicon-wafer-based PV technology accounted for more than $90 \%$ of the total production in 2017. Since silicon is an indirect bandgap semiconductor, silicon wafers need a thickness up to few hundreds of microns to fully absorb the longer wavelength light $[2,3]$. Compared with siliconbased PV, thin-film solar cells have significant advantages in raw material consumption and multiple scenarios application [4]. At present, the widely studied and commercialized thin-film solar cells, $\mathrm{Cu}$ (In, Ga)Se $\mathrm{S}_{2}$ (CIGS) and $\mathrm{CdTe}$, have achieved over $22 \%$ power conversion efficiency (PCE) [5]. Nevertheless, the rare elements (In, $\mathrm{Ga}$, and $\mathrm{Te}$ ) limit the large-scale production and application of these cells [6]. In this case, kesterite $\mathrm{Cu}_{2} \mathrm{ZnSn}\left(\mathrm{S}_{x}, \mathrm{Se}_{1-x}\right)_{4}$ (CZTSSe, $\left.0 \leq x \leq 1\right)$ has emerged as one of the most promising candidate materials, because of its ideal direct bandgap (1.0-1.5 eV), high optical absorption coefficient $\left(10^{4}-10^{5} \mathrm{~cm}^{-1}\right)$ and earth-abundant raw materials [7-11]. During the last decades, the efficiency of CZTSSe solar cell has been significantly increased from about $2.6 \%$ in 2001 to $12.6 \%$ in 2013 [12-14]. However, the development seems to be experiencing a bottleneck, without any significant breakthrough in efficiency during the past six years. Currently, the performance of kesterite solar cells is much far below the Shockley-Queisser (S-Q) limit [15]. For the further progress, it is crucial to deeply understand the performance loss mechanism of CZTSSe solar cells. Some research groups have contributed their comprehensions from different aspects in recent years [16-20].

Firstly, the non-ideal interface properties of the CZTSSe solar cell can limit the PV performance $[21,22]$. Both of the top CZTSSe/CdS interface and the bottom $\mathrm{Mo} /$ CZTSSe interface should be concerned. The bandgap of CZTSSe could be adjusted by changing the ratio $x$ of $\mathrm{S}$ and $\mathrm{Se}, x=\mathrm{S} /(\mathrm{S}+\mathrm{Se})$. When $x=1$, namely pure CZTS $\left(E_{\mathrm{g}}=1.5 \mathrm{eV}\right)$, a so-called "cliff-type" band alignment is formed between CZTS and CdS [23,24]. With such a negative conduction band offset $(\mathrm{CBO})$, high recombination between electrons injected into the buffer

\footnotetext{
${ }^{1}$ Key Laboratory for Renewable Energy, Beijing Key Laboratory for New Energy Materials and Devices, Institute of Physics, Chinese Academy of Sciences, Beijing 100190, China

${ }^{2}$ Center of Materials Science and Optoelectronics Engineering, University of Chinese Academy of Sciences, Beijing 100049, China

${ }^{3}$ School of Physics Science, University of Chinese Academy of Sciences, Beijing 100049, China

${ }^{4}$ Songshan Lake Materials Laboratory, Dongguan 523808, China

* Correspondence author (email: qbmeng@iphy.ac.cn)
} 
and holes in the CZTS may arise in the top interface on account of reduced recombination activation energy. Comparatively, when $x=0$, namely pure CZTSe $\left(E_{\mathrm{g}}=1.0 \mathrm{eV}\right)$, an electrically benign "spike-type" band alignment is formed [23]. Other buffer layers have also been attempted, and the CZTSSe solar cell based on $\operatorname{In}_{2} \mathrm{~S}_{3} /$ CdS double buffer layers also exhibited the highest efficiency in the latest report [25-28]. Regarding the bottom interface, CZTSSe could react with the standard back contact, Mo, during the necessary high-temperature sulfo-selenization, thus creating a $\mathrm{Mo}(\mathrm{S}, \mathrm{Se})_{2}$ thin film [2931]. The $\mathrm{Mo}(\mathrm{S}, \mathrm{Se})_{2}$ film is a double-edged sword, which could act as a buffer layer to promote the back contact but may introduce high series resistance when the film is too thick $[32,33]$. Besides, secondary phases, such as $\mathrm{ZnS}_{(\mathrm{e})}$, $\mathrm{SnS} \mathrm{S}_{(\mathrm{e})}$, and $\mathrm{Cu}_{2} \mathrm{~S}_{(\mathrm{e})}$, could be generated at this interface because of the reaction between CZTSSe and Mo [29]. Therefore, the non-ideal electrical properties of the top and bottom interfaces could be one of the causes for the performance loss of the cell. Although a series of efforts have been made to control and optimize the interfaces [32,34-36], it is still difficult to make substantial breakthrough and progress so far.

Apart from the interfaces, the CZTSSe absorber itself is a multiternary semiconductor, which possesses complicated defect properties. First-principles calculation to the intrinsic lattice defects in pure $\mathrm{Cu}_{2} \mathrm{ZnSnS}_{4}$ (CZTS) and pure $\mathrm{Cu}_{2} \mathrm{ZnSnSe}_{4}$ (CZTSe) have revealed that various isolated defects and self-compensated defect clusters widely exist in both stoichiometric and non-stoichiometric alloys [37]. The defects with low ionization level, including $\mathrm{V}_{\mathrm{Cu}}, \mathrm{Cu}_{\mathrm{Zn}},\left[\mathrm{Cu}_{\mathrm{Zn}}+\mathrm{Zn}_{\mathrm{Cu}}\right]$, could on the one hand enhance the intrinsic p-type conductivity, but on the other hand increase the band tail states. Experiments have exhibited that CZTSSe has much more band tail states than the parent compound CIGS [38]. The Cu/Zn antisite defect was once considered as the main reason for limiting the efficiency of CZTSSe devices, and various methods (such as elements substitution) have been used to suppress this defect, but recently this claim has been questioned [21,39-41]. Another kind of defects located deeply at the mid-gap, such as $\mathrm{Sn}_{\mathrm{Zn}}, \mathrm{V}_{\mathrm{S}},\left[2 \mathrm{Cu}_{\mathrm{Zn}}+\mathrm{Sn}_{\mathrm{Zn}}\right]$, could act as non-radiative recombination centers of photogenerated electron-hole pairs [42,43]. It is suggested that both the band tail states and the non-radiative recombination centers are detrimental to the cell performance, especially to the open-circuit voltage [41]. Honestly, we are still far away from clearly revealing the defect-related charge loss mechanisms, and it is also hard to experimentally identify and control the defects. Re- cently, new theoretical and experimental findings about the defect physics of the CZTSSe material have been reported, providing us with more opportunities to understand this material and the performance loss of the cell. For the CZTSSe community, it is urgent to systematically summarize current findings and understandings about the defect-related charge loss mechanism and to dialectically extract valuable information from the previously published numerous studies. This is the topic and aim of this review. We hope this review about exploration of the underlying mechanism of the efficiency loss could help the readers to better understand the material and device physics of the CZTSSe solar cell and to develop more effective approaches for the device performance improvement.

For clarity, this review is presented in five main sections in addition to the introduction and conclusion. Firstly, we will give a brief summary of the development history of the CZTSSe solar cell with a comparison with the CIGS cell. Secondly, we will introduce the band tail states and their widespread existence in CZTSSe. The following section will aim at the atom disorder in CZTSSe and its impact on device properties. Then, we will focus on the deep defects as effective non-radiative recombination centers in CZTSSe. Furthermore, the experimental characterization and controlling methods towards defects will be summed up in the last. In this review, we present dialectical discussions on previously reported theoretical and experimental results, and more importantly extract more abundant charge recombination dynamics information and provide our understandings on the charge recombination processes of the CZTSSe. These discussions may help recognize the status, deficiencies and the future direction of the study on the performance loss mechanism of the CZTSSe solar cell.

\section{DEVELOPMENT STATUS AND MAIN PROBLEM}

The efficiency of CZTSSe solar cell has indeed improved significantly over the past few decades, from $2.67 \%$ in 2001 to $12.6 \%$ in 2013 [12,13]. Fig. 1 shows the efficiency evolution of CZTSSe solar cells from year 0 (first reported working device) up to date, in comparison with the CIGS technology $[5,12,44-46]$. From this comparison, we can clearly see that the kesterite technology is still in the primary development stage, with no more than twenty years' history. CIGS technology is more mature with more than forty years of evolution. Interestingly, the CZTSSe cell exhibited a slightly faster development trend in the initial twelve years compared with the CIGS. This is 


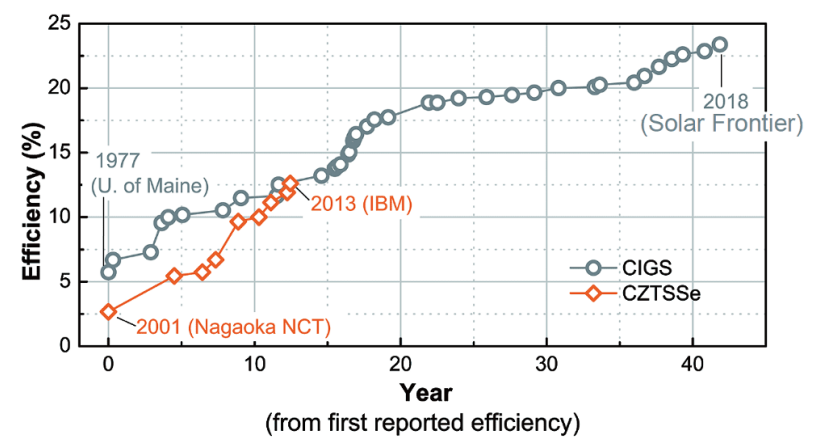

Figure 1 Efficiency evolution of CZTSSe and CIGS from the first reported working solar cell. Year 0 is 1977 for CIGS and 2001 for CZTSSe.

a positive signal although the CZTSSe cell is experiencing a bottleneck. This bottleneck not only arises from the cell itself but also correlates to the limited research community. The emerging and rapid development of the perovskite solar cell from 2013 has affected the research enthusiasm of the CZTSSe cell more or less [5]. Nonetheless, we can still see the development promise of the CZTSSe from the history of CIGS and CZTSSe if the research community can be expanded and more efforts can be gathered together.

Performance parameters including short-circuit current density $\left(J_{\mathrm{SC}}\right)$, open-circuit voltage $\left(V_{\mathrm{OC}}\right)$ and fill factor
(FF) of the reported CZTSSe solar cells with efficiencies above $11 \%$ are summarized and shown in Fig. $2 \mathrm{a}-\mathrm{d}$ [13,28,47-63]. These devices were prepared by different processes, including non-vacuum (i.e., hydrazine-based and non-hydrazine spin coating) and vacuum (i.e., coevaporation, and sputtering) methods. Besides the hydrazine-based method, the sputtering method also produced highly efficient CZTSSe devices, $12.6 \%$ for a small cell size and $11.3 \%$ for a larger cell size $\left(1.176 \mathrm{~cm}^{2}\right)$, as shown in Fig. 2d [60]. Obviously, the highest efficiency was achieved in CZTSSe absorber with low $S$ content $\left(E_{\mathrm{g}}\right.$ $\approx 1.1 \mathrm{eV}$ ). This depends on the different defect nature of CZTS and CZTSe. The energy level of point defects in CZTS is usually deeper than that in CZTSe, which may lead to more non-radiative recombination loss in the absorber [37]. High efficiency seldom occurs in the bandgap of 1.2-1.3 eV regime because CZTSSe materials with a medium $\mathrm{S} /(\mathrm{S}+\mathrm{Se})$ ratio usually possess a high formation energy and serious phase separation [24]. Meanwhile, the change of the $\mathrm{CBO}$ at buffer/absorber interface caused by different $\mathrm{S} /(\mathrm{S}+\mathrm{Se})$ ratios will also affect the device efficiency [64]. By comparing these performance parameters with the S-Q theoretical limit (Fig. 2a-d), it is clearly seen that the efficiency loss mainly lies in the $V_{\mathrm{OC}}$ and the FF [65]. In particular, the $V_{\mathrm{OC}}$ is less than $60 \%$ of the S-Q limit. The $V_{\mathrm{OC}}$ deficit $\left(E_{\mathrm{g}} / q-V_{\mathrm{OC}}\right.$,

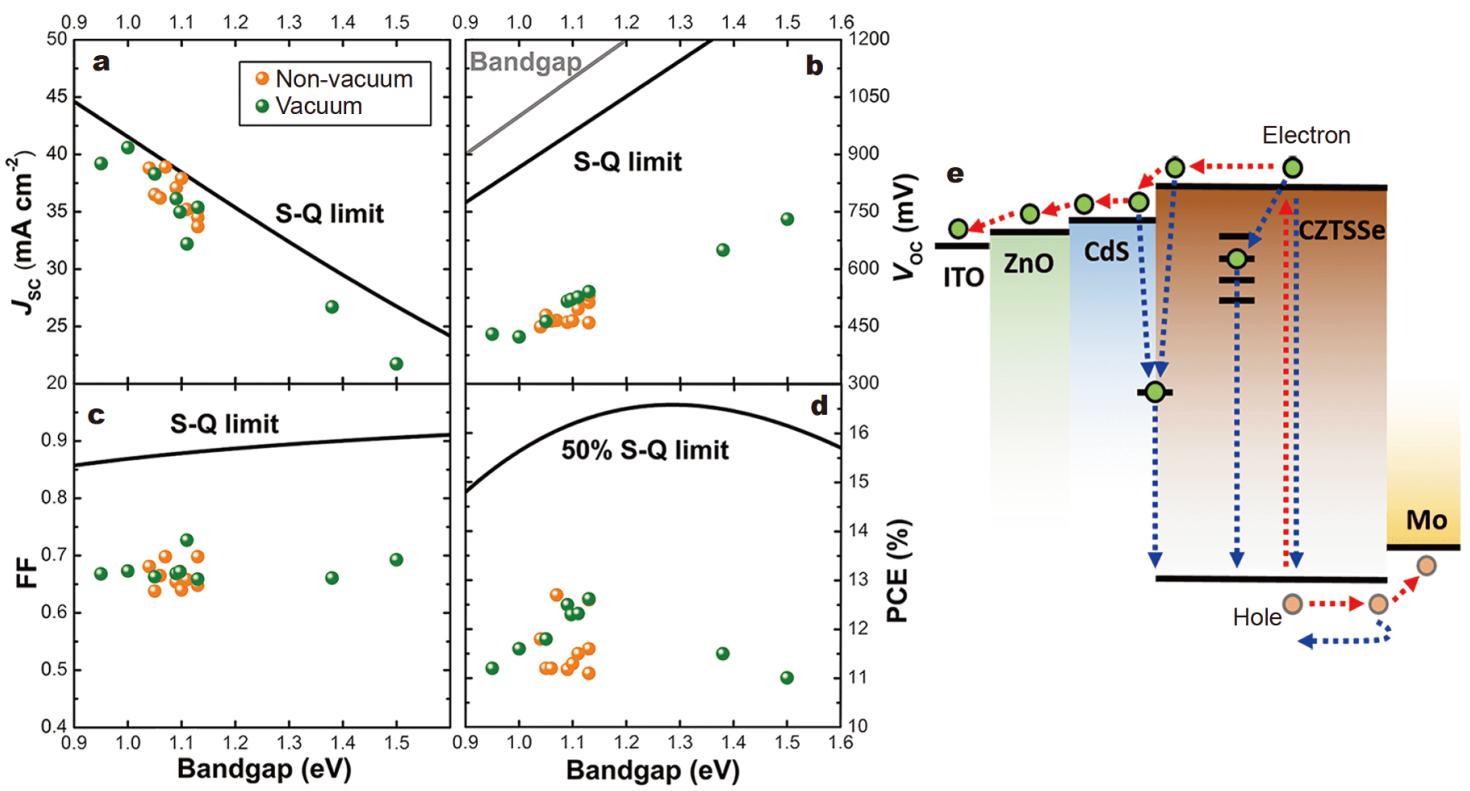

Figure 2 The single-junction solar cell parameters. (a) $J_{\mathrm{SC}}$, (b) $V_{\mathrm{OC}}$, (c) FF, (d) PCE are shown as a function of bandgap energy according to the S-Q limit (black solid lines) and experimental values for reported highly efficient (PCE $>11 \%)$ CZTSSe solar cells. The green dots represent devices made by vacuum processes, and the orange dots are for the devices made by non-vacuum processes. (e) Schematic diagram of carrier dynamics processes within a CZTSSe solar cell. 
where $q$ is the charge of an electron) of CZTSSe $(>0.57 \mathrm{~V})$ is much larger than that of the parent CIGS solar cell $(<0.40 \mathrm{~V})[21]$.

The $V_{\mathrm{OC}}$ of a solar cell refers to the potential difference formed by carriers accumulated in the front and back electrodes. As shown in Fig. 2e, the photons are incident from the front surface of the solar cell, transmitted through the window layer and the buffer layer, and then absorbed by CZTSSe, thereby generating free electrons and holes. Due to the presence of the built-in electric field, the photogenerated carriers in the depletion region are rapidly separated. The electrons drift into the CdS and $\mathrm{ZnO}$ layers, and are laterally transported within the indium tin oxide (ITO) or Al-doped $\mathrm{ZnO}$ (AZO) layer and eventually collected by the front electrode. The carrier recombination loss in the bulk material and at the charge extraction interfaces can cause a large $V_{\mathrm{OC}}$ deficit [66].

Many efforts have been made to clarify the origins of large $V_{\mathrm{OC}}$ deficit, which resulted in various interpretations and ongoing debates. Some time ago, researchers generally believed that the high-density shallow defects (i.e., $\left.\mathrm{Cu}_{\mathrm{Zn}}, \mathrm{Zn}_{\mathrm{Cu}}\right)$, which are formed by widespread atomic disorder in CZTSSe, cause band tail states and reduction of the bandgap of the bulk material [41]. However, some recent studies show that the deep defects with strong carrier capture ability (i.e., $\mathrm{Sn}_{\mathrm{Zn}}{ }^{2+}, \mathrm{V}_{\mathrm{S}}$ ) are killer defects for $V_{\mathrm{OC}}$ deficit $[42,43]$. It is critical for achieving efficiency breakthroughs to analyze the properties of different defects and their effects on device performance, which will be reviewed and discussed in detail below.

\section{BAND TAIL STATES}

Band tailing in the CZTSSe film has been widely verified by experiments $[38,67,68]$. Band tailing arises because the density of states (DOS) in the bandgap, especially near the band edge, is usually not zero, which leads to the narrowing of the effective bandgap, as shown in Fig. 3a [69]. Fig. $3 \mathrm{~b}$ shows that the falling edge of internal quantum efficiency (IQE) curve of the CZTSSe solar cell is severely tailed, and the peak position of film photoluminescence (PL) is significantly red-shifted compared with the bandgap [38]. These are representative signatures of the band tailing effect.

Theoretically, the band tail states mainly arise from
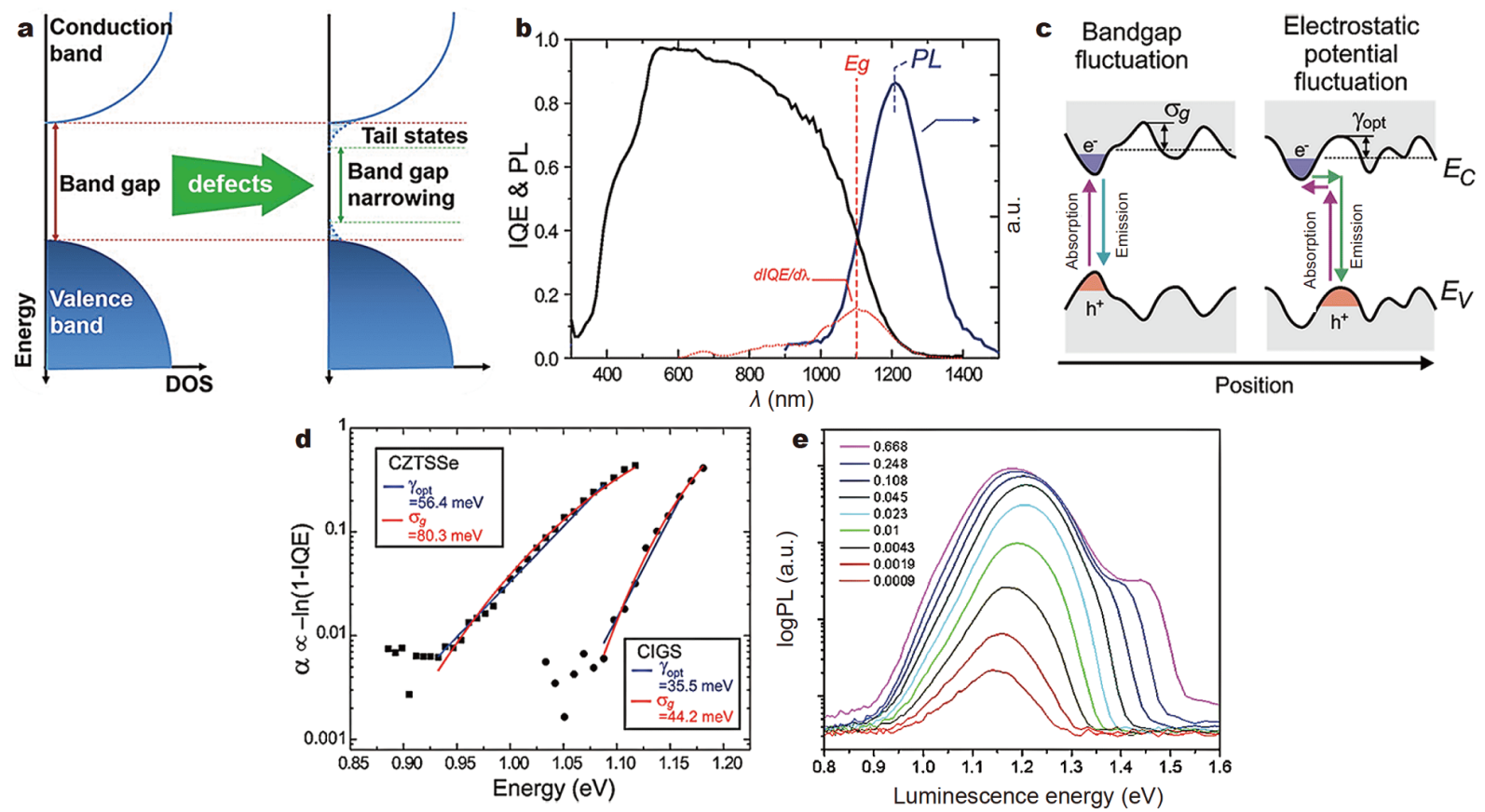

Figure 3 (a) Schematic of total DOS plot in conventional semiconductor materials and modified DOS plot in disordered materials. Reprinted with permission from Ref. [69]. Copyright 2017, Wiley-VCH. (b) The IQE, the bandgap determined from the IQE inflection point, and the PL spectra (taken using a $532 \mathrm{~nm}$ solid state laser) of high-performance CZTSSe solar cell (10.7\% efficiency). (c) Schematic of bandgap fluctuations (left) and electrostatic potential fluctuations (right). (d) Absorption coefficient (as deduced from the IQE) $v s$. photon energy plots below the bandgap energy of CZTSSe (10.7\% efficiency) and CIGS (15.0\% efficiency) solar cells. Fits corresponding to the electrostatic potential fluctuations and bandgap fluctuations models are shown by blue and red lines, respectively. Reprinted with permission from Ref. [38]. Copyright 2013, AIP publishing. (e) PL spectra of a CZTS device ( $8.3 \%$ efficiency) as a function of excited laser power (identified in legend, $\mathrm{W} \mathrm{cm}{ }^{-2}$ ) at $4 \mathrm{~K}$. Reprinted with permission from Ref. [70]. Copyright 2013, AIP publishing. 
spatial fluctuation of bandgap or electrostatic potential in the semiconductor as seen in Fig. 3c [38]. In the case of pure bandgap fluctuations, the spatial variation of the conduction and valence bands are inversely correlated. This kind of fluctuations originates from non-uniformity of the components, disorder of the structure or coexistence of different lattice phases. For example, the distribution of S and Se atoms in CZTSSe may be uneven or random, forming S-rich or Se-rich region. The bandgap of the Se-rich region is smaller than that of the S-rich region. Both photogenerated electrons and holes can spontaneously transfer to the Se-rich region driven by the energy gradient. Another example, the formation of the antisite defects and the charge compensation pairs of $\mathrm{Cu}$ and $\mathrm{Zn}$ in CZTSSe will simultaneously introduce defect states below the conduction band minimum (CBM) and above the valence band maximum (VBM), which is equivalent to reducing the local bandgap of the material. For any direct bandgap semiconductor without band tail states, the absorption coefficient is given by $\alpha \propto \sqrt{\hbar \omega-E_{\mathrm{g}}} / \hbar \omega$, where $\hbar \omega$ is the incident photon energy. For bandgap fluctuations, the above equation should be modified by turning $E_{\mathrm{g}}$ into a Gaussian probability distribution function. So the absorption coefficient is described as

$\alpha \propto \int_{0}^{\infty} \frac{1}{\sigma_{\mathrm{g}} \sqrt{2 \pi}} \exp \left(-\frac{1}{2}\left(\frac{E_{\mathrm{g}}-E_{\mathrm{g}, \text { mean }}}{\sigma_{\mathrm{g}}}\right)^{2}\right)\left(\frac{\sqrt{\hbar \omega-E_{\mathrm{g}}}}{\hbar \omega}\right) \mathrm{d} E_{\mathrm{g}}$,

where $E_{\mathrm{g} \text { mean }}$ and $\sigma_{\mathrm{g}}$ are the mean and the standard deviation of the spatially varying bandgaps, respectively. Obviously, the bandgap fluctuations cause that the photons with energy lower than the true $E_{\mathrm{g}}$ can also produce photogenerated carriers, hence easily accounting for the experimentally observed IQE curve tailing.
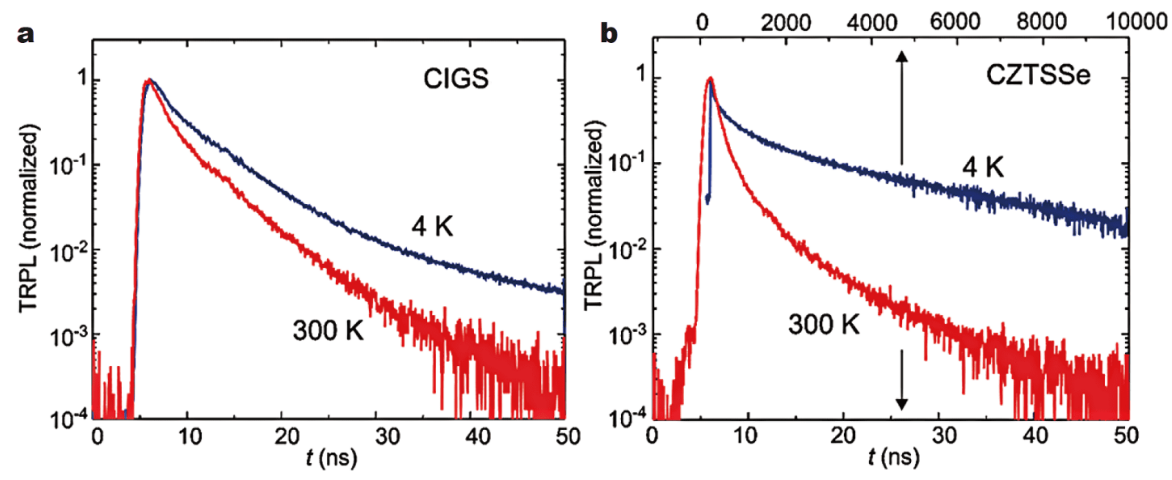

Figure 4 Time-resolved PL (TRPL) curves at 4 and $300 \mathrm{~K}$ for (a) CIGS and (b) CZTSSe solar cells. Reprinted with permission from Ref. [38]. Copyright 2013, AIP publishing. 
deviation of CZTSSe are roughly twice those of CIGS. Mattheis et al. [73] used PL spectra to estimate the fluctuations. Under the assumption that the length scale of the fluctuations is smaller than the diffusion length, the red shift of the PL peak can be calculated with $\sigma_{\mathrm{g}}$ of $\sim 40$ and $\sim 150 \mathrm{meV}$ for CIGS and CZTSSe, respectively. Although the IQE and PL tests cannot distinguish between bandgap fluctuations and electrostatic potential fluctuations, it is undeniable that the band tail states of CZTSSe are much more severe than that of CIGS, which can account for the larger $V_{\mathrm{OC}}$ deficit to some extent.

Excitation intensity-dependent PL spectra presented more direct evidence of the existence of tail or subgap states within the CZTSSe [70]. As reported in Fig. 3e, at low excitation power, the PL peak was centered at $1.15 \mathrm{eV}$, showing a giant red shift of approximately $0.35 \mathrm{eV}$. As the excitation power increased, the peak position blue-shifted and gradually saturated, showing a state filling behavior. In the meanwhile, a new higherenergy peak appeared at $1.45 \mathrm{eV}$, close to CZTS bandgap. These results mean that under normal working conditions, the photogenerated charge of the cell is mainly localized within the subgap states. The resulting severe non-radiative recombination and charge transportation loss eventually lead to the $V_{\mathrm{OC}}$ loss of the device.

\section{DISORDER}

\section{$\mathrm{Cu} / \mathrm{Zn}$ disorder: formation}

It is now generally accepted that CZTS crystals adopt a kesterite (KS) structure (space group I4), which is a tetragonal derivative of the cubic sphalerite $\mathrm{ZnS}$ structure [23]. When the $\mathrm{Cu}$ atoms at the $(1 / 2,0,1 / 4),(0,1 / 2,3 / 4)$ position are interchanged with the $\mathrm{Zn}$ atoms at the $(1 / 2$, $1 / 2,0),(0,0,1 / 2)$ position, the stannite (ST) structure (space group $I \overline{4} 2 \mathrm{~m}$ ) CZTS is obtained (Table 1 and Fig. 5a) [74,75]. First principle calculations show that the KS structure has lower energy and is more stable in the thermodynamic equilibrium state, while the energy of the ST structure is only $4.6 \mathrm{meV}$ atom $^{-1}$ higher than that of the KS structure [74]. As limited by the dynamic process during the high-temperature annealing and cooling, the CZTSSe lattice may not be completely relaxed to the KS structure and the final product may be in a mixture structure comprised of KS and ST or in a $\mathrm{Cu} / \mathrm{Zn}$ antisite random state. Fig. $5 \mathrm{~b}$ shows the theoretically calculated formation energy of a series of point defects in the CZTSSe [37]. It is clear that $\mathrm{Cu}_{\mathrm{Zn}}$ antisite possesses the lowest formation energy of $<0.25 \mathrm{eV}$ in both CZTS and CZTSe. Moreover, the formation energy of $\left[\mathrm{Cu}_{\mathrm{Zn}}{ }^{-}+\mathrm{Zn}_{\mathrm{Cu}}{ }^{+}\right]$ $\left(\left[\mathrm{Cu}_{\mathrm{Zn}}+\mathrm{Zn}_{\mathrm{Cu}}\right]\right)$ defect cluster is extremely low of $0.2 \mathrm{eV}$ and independent to the element chemical potential. This means that the $\mathrm{Cu} / \mathrm{Zn}$ disorder is always easy to form in the CZTSSe lattice whatever the element composition is.

\section{$\mathrm{Cu} / \mathrm{Zn}$ disorder: characterization}

Due to the similarity of $\mathrm{Cu}$ and $\mathrm{Zn}$ in atomic number and size, these disordered structures are not distinguishable by using standard X-ray diffraction (XRD) techniques. Neutron diffraction and nuclear magnetic resonance (NMR) can be used to identify the cation distribution in the crystal structure, and have confirmed the widely existing disorder between $\mathrm{Cu}$ and $\mathrm{Zn}$ in the $z=1 / 4$ and $z=3 / 4$ $\mathrm{Cu} / \mathrm{Zn}$ planes [76-78]. However, neutron diffraction and NMR are unsuitable for thin film samples. How to accurately quantify the $\mathrm{Cu} / \mathrm{Zn}$ disorder in film samples is still a challenge for CZTSSe solar cell investigations.

The classic description of order-disorder transitions in crystalline materials was made by Bragg and Williams [79]. According to them, the crystal is in a state of dynamical equilibrium, where the rate at which atoms are thrown out of ordered positions into disordered positions by thermal fluctuations is equal to the rate at which the reverse process takes place. The perfectly ordered structure with a lowest energy is the ground state, while thermal fluctuations have the effect of creating a random atomic arrangement, leading to a temperature-dependent equilibrium ordering degree. The degree of order can be quantified by a long-range order parameter, $S$, which ranges from 1 (perfectly order) to 0 (totally disorder).

Table 1 Atomic occupancies, calculated lattice sizes and energies corresponding to different lattice structures of CZTS [74]

\begin{tabular}{|c|c|c|c|c|c|c|c|}
\hline Structure & $\mathrm{Cu}$ & $\mathrm{Zn}$ & $\mathrm{Sn}$ & $a(\AA)$ & $c(\AA)$ & $c / a$ & Energy (meV per atom) \\
\hline CZTS KS & $\begin{array}{c}(0,0,0) \\
(1 / 2,1 / 2,1 / 2) \\
(1 / 2,0,1 / 4) \\
(0,1 / 2,3 / 4)\end{array}$ & $\begin{array}{c}(1 / 2,1 / 2,0) \\
(0,0,1 / 2)\end{array}$ & $\begin{array}{l}(0,1 / 2,1 / 4) \\
(1 / 2,0,3 / 4)\end{array}$ & 5.443 & 10.786 & 1.982 & 0 \\
\hline CZTS ST & $\begin{array}{c}(0,0,0) \\
(1 / 2,1 / 2,1 / 2) \\
(1 / 2,1 / 2,0) \\
(0,0,1 / 2)\end{array}$ & $\begin{array}{l}(1 / 2,0,1 / 4) \\
(0,1 / 2,3 / 4)\end{array}$ & $\begin{array}{l}(0,1 / 2,1 / 4) \\
(1 / 2,0,3 / 4)\end{array}$ & 5.403 & 10.932 & 2.023 & 4.6 \\
\hline
\end{tabular}



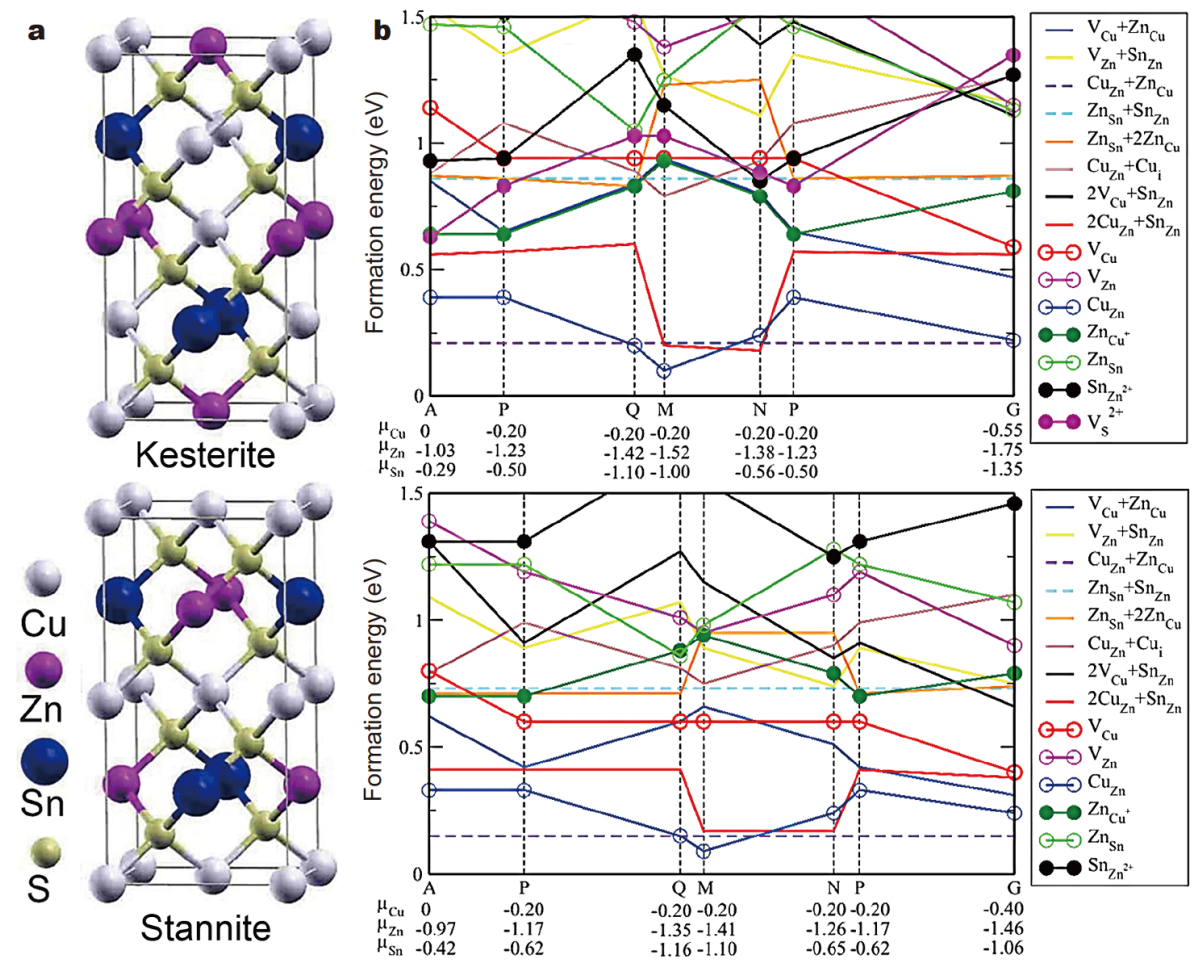

Figure 5 (a) Crystal structures of kesterite and ST CZTS. Reprinted with permission from Ref. [75]. Copyright 2009, AIP publishing. (b) The formation energy of defects in CZTS (top) and CZTSe (bottom) as a function of the chemical potential. Reprinted with permission from Ref. [37]. Copyright 2013, Wiley-VCH.

This method has been used to study the $\mathrm{Cu} / \mathrm{Zn}$ order/ disorder of the CZTSSe. Considering a $\mathrm{Cu} / \mathrm{Zn}$ plane of the kesterite, the long-range order parameter can be descripted as $S=2\left(P_{\mathrm{Cu}}{ }^{\mathrm{Cu}}-1 / 2\right) . P_{\mathrm{Cu}}{ }^{\mathrm{Cu}}$ is the probability that a $\mathrm{Cu}$ atom occupies its native site, which decreases from 1 in perfectly ordered to 0.5 in fully disordered material. In Vineyard's theory of order-disorder kinetics [80], the order parameter equilibrium value, $S_{\text {eqm }}$, is a function of temperature: $S_{\text {eqm }}$ equals 1 at absolute $0 \mathrm{~K}$. As temperature increases, $S_{\text {eqm }}$ drops and falls rapidly to zero when approaching a certain critical temperature, $T_{\mathrm{C}}$, as shown with the dashed line in Fig. 6a [81]. However, in practical experiments, the crystal structure cannot be completely relaxed to equilibrium state during the annealing and cooling processes. The solid curves in Fig. 6a illustrate the effect of annealing to a sample with an initially low degree of ordering (non-equilibrium), $S_{0}$, for two different time durations $t_{1}$ and $t_{2}\left(t_{1}>t_{2}\right)$. In Fig. $6 a$, the evolution of the long-range order parameter is divided into three stages. (I) When the temperature is much lower than $T_{C}$, thermal fluctuations mainly cause atomic vibration, which is not high enough to cause atomic positional interchange. (II) At intermediate temperatures, the order parameter in- creases towards $S_{\text {eqm }}$ with the occurrence of atomic exchange. (III) As the temperature approaching $T_{C}, S$ drops rapidly and then remains zero at higher temperatures. Annealing for a longer period of time allows the crystal structure to obtain a fuller relaxation to approach the equilibrium state. Thus, in stage II, $S\left(T, t_{1}\right)$ is higher than $S\left(T, t_{2}\right)$. In theory, infinite-time annealing can bring the crystal to the equilibrium state, but this is not realistic in practical preparations of CZTSSe absorbers.

Scragg et al. [81] proposed that near-resonant Raman scattering can detect the degree of $\mathrm{Cu} / \mathrm{Zn}$ disorder. The Raman scattering depends on the symmetry of the crystal structure, the strength of the chemical bonds and the mass and charge of the constituent elements, which is sensitive to the local atomic environment [82]. In their study [81], two CZTS powder samples which were prepared at different cooling rates were firstly measured by NMR to make an evaluation of the $\mathrm{Cu} / \mathrm{Zn}$ disorder. The slowly cooling sample (sample VS in Fig. 6b) was proved to be highly ordered, while the other sample (sample VF) that quenched in ice-water was disordered. They then collected the Raman spectra of these two samples excited at $785 \mathrm{~nm}$, as shown in Fig. 6b. It can be clearly seen that 

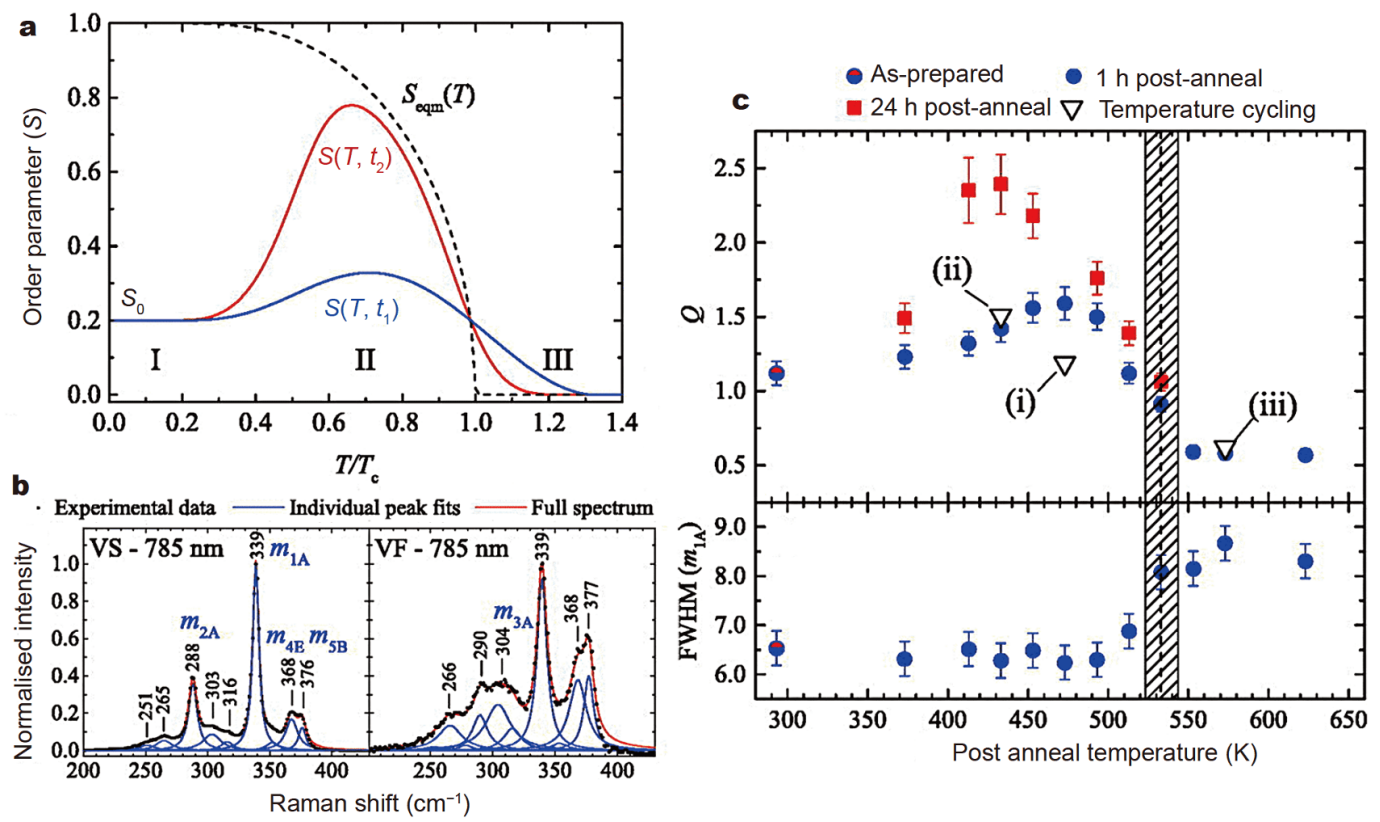

Figure 6 (a) The curves of the order degree, $S$, with the temperature. The dashed line indicates the equilibrium case. The solid lines show the effect of annealing initially disordered samples for fixed time periods $t_{1}$ and $t_{2}\left(t_{1}>t_{2}\right)$. (b) Raman spectra with peak fitting for stoichiometric CZTS powder reference samples, VS (slowly cooled, ordered) and VF (rapidly cooled, disordered), with excitation wavelength of $785 \mathrm{~nm}$. (c) Variation in $Q$ for initially identical CZTS films post-annealed for different time periods (top). The triangles show the effect of temperature cycling on a single sample to test the reversibility of changes in $Q$. The full width at half maximum (FWHM) of the main Raman A mode for the $1 \mathrm{~h}$ post-annealed samples (bottom). The shaded region indicates the probable location of the critical temperature $T_{\mathrm{C}}$. Reprinted with permission from Ref. [81]. Copyright 2014, AIP publishing.

the Raman spectra are different from each other. Sample VF exhibited a larger full width at half maximum (FWHM) of the main A mode $\left(m_{1 \mathrm{~A}}\right)$ at $\sim 339 \mathrm{~cm}^{-1}$. The second A mode $\left(m_{2 \mathrm{~A}}\right)$ at $\sim 288 \mathrm{~cm}^{-1}$ was about twice as strong as the $\mathrm{E}$ and $\mathrm{B}$ modes at 368 and $376 \mathrm{~cm}^{-1}\left(m_{4 \mathrm{E}}\right.$ and $\left.m_{5 \mathrm{~B}}\right)$. Comparatively, for sample VS, the relative intensity of $m_{2 \mathrm{~A}}$ was significantly increased compared with that of $m_{3 \mathrm{~A}}$ mode, and both the $m_{4 \mathrm{E}}$ and $m_{5 \mathrm{~B}}$ modes were obviously suppressed.

Based on the above observations, Scragg et al. [81] extracted two important parameters from the Raman spectra. One is the $Q$, which is defined as $I\left(m_{2 \mathrm{~A}}\right) / I\left(m_{3 \mathrm{~A}}\right)$, where $I(m)$ is the intensity of certain Raman mode derived from full spectrum fitting, and the other parameter is the FWHM of $m_{1 \mathrm{~A}}$. The relationship between $Q$ and annealing condition was obtained as in Fig. 6c, which showed a similar shape to the curves of $S(T, t)$. Together with more multi-step annealing experiment, they found that the parameter $Q$ can be used to reflect the $\mathrm{Cu} / \mathrm{Zn}$ disorder of CZTS film, that is, a larger $Q$ represents a more ordered structure. In addition, the estimated $T_{\mathrm{C}}$ of pure CZTS is $533 \pm 10 \mathrm{~K}\left(260 \pm 10^{\circ} \mathrm{C}\right)$. As seen in Fig. $6 \mathrm{c}$, the FWHM of the main $m_{1 \mathrm{~A}}$ mode also increased rapidly at $\sim 533 \mathrm{~K}$, further supporting the above finding. It is worth noting that the Raman scattering can be influenced by the bandgap and composition of CZTSSe, which makes it unrealistic to directly use the $Q$ value to compare the degree of order between the samples with different compositions.

\section{$\mathrm{Cu} / \mathrm{Zn}$ disorder: influence}

Based on the observation of structural changes induced by thermal treatment, Rey et al. [83] investigated the variation of the optical bandgap of pure CZTSe as a function of the annealing temperature. After successive annealing/quenching of the sample, the state before quenching can be sustained and detected. As shown in Fig. $7 \mathrm{a}$, the change of $E_{\mathrm{g}}$ with the temperature was completely reversible, which helped to exclude the possible influence of the formation of secondary phases, the loss of element, and the contamination of glass substrate during the annealing process. Further, the calculated shape of equilibrium long-range order parameter $\left(S_{\text {eqm }}\right)$ $v s$. $T$ exhibited a good agreement to the measured changes of $E_{\mathrm{g}} \nu s . T$ (Fig. 7b), which means that the $\mathrm{Cu} / \mathrm{Zn}$ disorder has a direct influence on the $E_{g}$. Ordering the atomic 

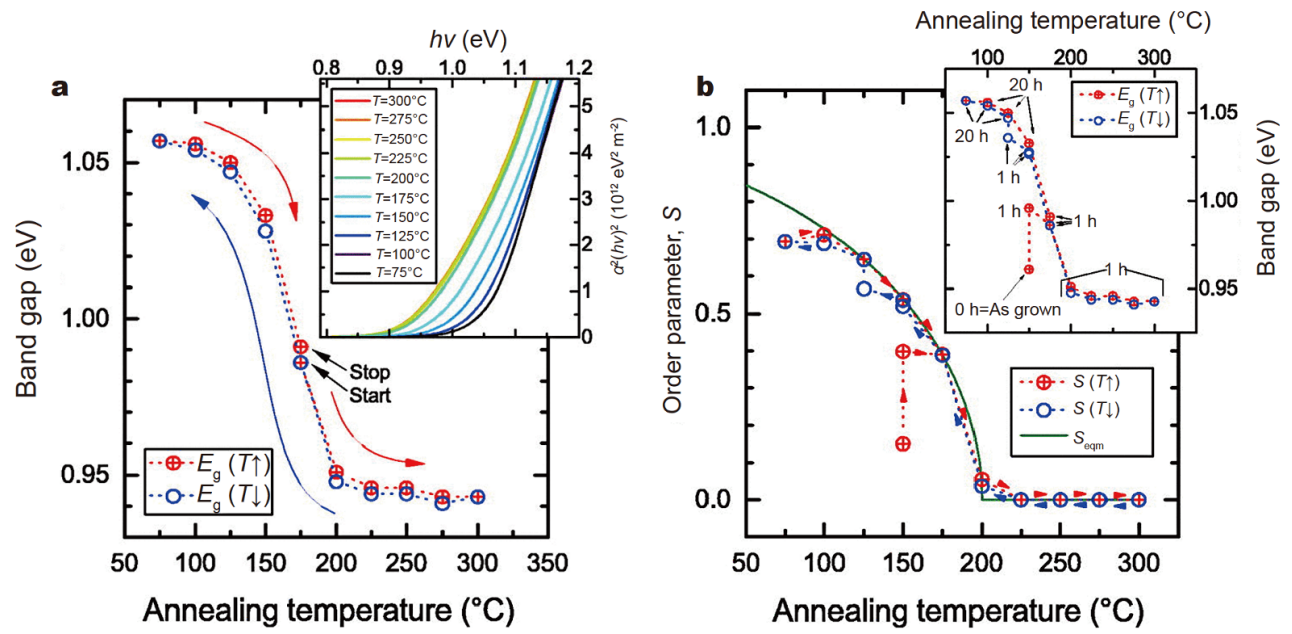

Figure 7 (a) Evolution of the CZTSe bandgap with the temperature during the annealing/quenching sequence. In the inset, Tauc's plots for different temperatures are presented. (b) Calculated evolution of the long-range order parameter during successive annealing treatments. The inset presents the evolution of $E_{\mathrm{g}}$ for the same annealing sequence. Annealing times (dwell times) are shown as labels. Reprinted with permission from Ref. [83]. Copyright 2014, AIP publishing.

arrangements of the CZTSe can increase the $E_{\mathrm{g}}$ by about $110 \mathrm{meV}$ as compared with the fully disordered material, and the estimated $T_{\mathrm{C}}$ of pure CZTSe is $200 \pm 20^{\circ} \mathrm{C}(473 \pm$ $20 \mathrm{~K})$, lower than that of pure CZTS. They also calculated that the $E_{\mathrm{g}}$ can be decreased by $24 \mathrm{meV}$ when the density of the $\left[\mathrm{Cu}_{\mathrm{Zn}}+\mathrm{Zn}_{\mathrm{Cu}}\right]$ defect cluster reaches $3.4 \times 10^{20} \mathrm{~cm}^{-3}$.

Despite these efforts, the influence of $\mathrm{Cu} / \mathrm{Zn}$ disorder on the $E_{\mathrm{g}}$ has not been clearly clarified because various research groups sometimes give different theoretical or experimental results. Chen et al. [37] calculated the band edge shift caused by one $\left[\mathrm{Cu}_{\mathrm{Zn}}+\mathrm{Zn}_{\mathrm{Cu}}\right]$ cluster in the 128atom supercell of CZTS and CZTSe and found that a high population of $\left[\mathrm{Cu}_{\mathrm{Zn}}+\mathrm{Zn}_{\mathrm{Cu}}\right]$ cluster can indeed decrease the optical bandgap. Interestingly, other deep defect clusters, like $\left[\mathrm{Sn}_{\mathrm{Cu}}+\mathrm{Cu}_{\mathrm{Sn}}\right],\left[\mathrm{Sn}_{\mathrm{Zn}}+\mathrm{Zn}_{\mathrm{Sn}}\right]$ and $\left[\mathrm{Sn}_{\mathrm{Zn}}+2 \mathrm{Cu}_{\mathrm{Zn}}\right]$, have a more significant impact on the bandgap. Huang et al. [84] reported that when a 64-atom CZTS supercell contains one $\left[\mathrm{Cu}_{\mathrm{Zn}}+\mathrm{Zn}_{\mathrm{Cu}}\right]$ cluster, the bandgap will be reduced by approximately $110 \mathrm{meV}$. Comparatively, the cluster $\left[\mathrm{Zn}_{\mathrm{Cu}}+\mathrm{V}_{\mathrm{Cu}}\right]$ was found to be able to increase the $E_{\mathrm{g}}$ by $70 \mathrm{meV}$. The presence of $\mathrm{Cu}$-poor $\left[\mathrm{Zn}_{\mathrm{Cu}}+\mathrm{V}_{\mathrm{Cu}}\right]$ cluster can lower the formation energy of the antisite $\left[\mathrm{Cu}_{\mathrm{Zn}}\right.$ $\left.+\mathrm{Zn}_{\mathrm{Cu}}\right]$ cluster, which may lead to a complicated influence on the $E_{\mathrm{g}}$. Thus, the bandgap evolutions observed by Rey et al. [83] should be a result of the joint influence of various defects.

It is more widely recognized that the increase of $\mathrm{Cu} / \mathrm{Zn}$ disorder could result in more band tail states. As charged defects, isolated $\mathrm{Cu}_{\mathrm{Zn}}{ }^{-}$or $\mathrm{Zn}_{\mathrm{Cu}}{ }^{+}$can induce the electrostatic potential fluctuations, which were considered as an important factor limiting CZTSSe solar cell efficiency by Gokmen et al. [38]. The uneven distribution of $\left[\mathrm{Cu}_{\mathrm{Zn}}\right.$ $\left.+\mathrm{Zn}_{\mathrm{Cu}}\right]$ clusters will lead to the bandgap fluctuations. Both these two types of fluctuations can locally separate the electron and hole and thus suppress the radiative recombination. Scragg et al. [85] carried out excitationintensity-dependent PL measurements on ordered $(S \sim 0.8)$ and disordered $(S \sim 0)$ CZTS samples (Fig. 8a). When increasing the excitation intensity, the ordered sample exhibited a higher PL response. The lower PL response of the disordered sample may also come from the severe non-radiative recombination induced by the tail states.

According to our discussion above, the band tail states may lead to the $V_{\mathrm{OC}}$ deficit of the device. In this case, it is a question how much the band tail states caused by $\mathrm{Cu} /$ $\mathrm{Zn}$ disorder can influence the $V_{\mathrm{OC}}$. Rau et al. [86] proposed to quantify the relationship between bandgap fluctuations and the $V_{\mathrm{OC}}$, that is

$V_{\mathrm{OC}}=\frac{E_{\mathrm{g}}}{q}-\frac{\sigma_{\mathrm{g}}^{2} q}{2 k T}-\frac{k T}{q} \ln \left(\frac{J_{00}}{J_{\mathrm{SC}}}\right)$,

where $J_{00}$ is the pre-exponential factor of the dark saturation current density, and $J_{\mathrm{SC}}$ is the short circuit current density. It was assumed that at a given anion ratio, the amplitude of bandgap fluctuations caused by $\mathrm{Cu} / \mathrm{Zn}$ disorder is $150 \mathrm{meV}$, corresponding to a reasonable $\sigma_{\mathrm{g}}=150 / 4=38 \mathrm{meV}$. Taking this value into Equation (4), it can be found that the maximum $V_{\mathrm{OC}}$ deficit is only $47 \mathrm{mV}$ [41]. Apparently, this value is negligible compared 

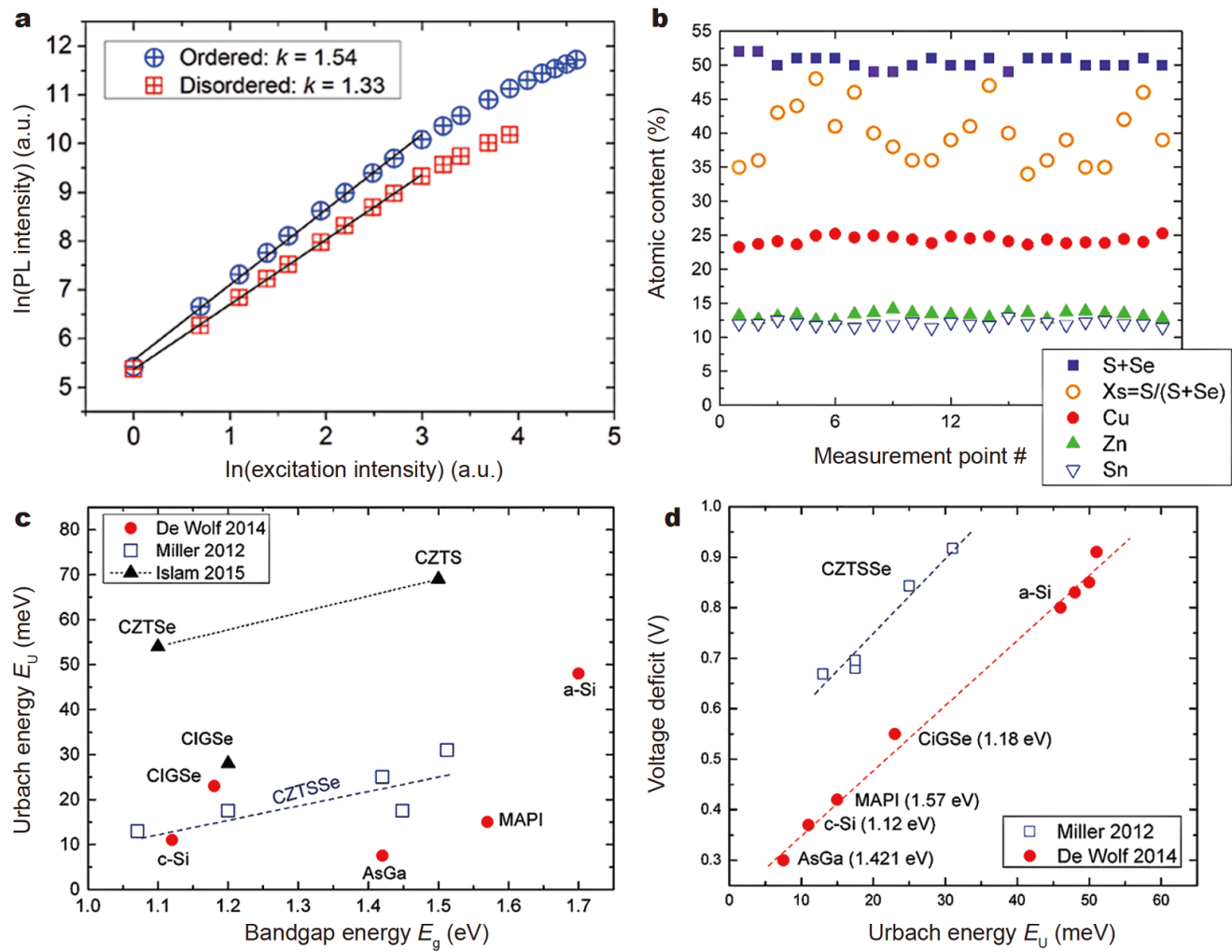

Figure 8 (a) Dependence of PL intensity on excitation intensity for ordered $(S \sim 0.8)$ and disordered $(S \sim 0)$ pieces of a CZTS sample. The straight lines indicate the regions of data from which the $k$-factors were calculated. Reprinted with permission from Ref. [85]. Copyright 2015, Wiley-VCH. (b) Grain-to-grain variation evaluated from 24 data points measured on various grains from a few sections, with 1 data point per grain. The relationship between the bandgap energy and Urbach energy $E_{\mathrm{U}}(\mathrm{c})$, and the relationship between Urbach energy $E_{\mathrm{U}}$ and the lowest voltage deficit (d) for various photovoltaic materials reported. Reprinted with permission from Ref. [41]. Copyright 2016, Wiley-VCH.

with current $V_{\mathrm{OC}}$ deficit of the CZTSSe device in the experiment $(>570 \mathrm{mV})$. In addition, although the bandgap and the $V_{\mathrm{OC}}$ can indeed be increased more or less by suppressing the $\mathrm{Cu} / \mathrm{Zn}$ disordering, the reduction in $V_{\mathrm{OC}}$ deficit is very limited until now. These studies show that whether the large $V_{\mathrm{OC}}$ loss occurring in the CZTSSe solar cell arises from the $\mathrm{Cu} / \mathrm{Zn}$ disorder is still an open question.

\section{S/Se disorder}

$\mathrm{S} / \mathrm{Se}$ disorder, that is, non-uniform anionic distribution, could also exist in the CZTSSe system [87]. Currently, the CZTSSe thin films are mainly prepared through a post sulfo-selenization route; during this process, slow atomic diffusion may result in different concentrations of anions inside and outside the grain. The scanning transmission electron microscopy-energy dispersive X-ray spectroscopy (STEM-EDX) characterization proved that the grains of the active absorber exhibited different $\mathrm{S} /(\mathrm{S}+\mathrm{Se})$ ratios as seen in Fig. 8b [41]; the Se concentration on the upper surface was higher than that on the bottom surface. Such S/Se disorder will lead to bandgap fluctuations in the real-space of the absorber. Its influence on the $V_{\mathrm{OC}}$ was also estimated by Equation (4). The calculation results showed that the S/Se non-uniformity and the spatial bandgap fluctuations only made a negligible contribution (less than 2.8\%) to the $V_{\mathrm{OC}}$ deficit [41].

Based on the above discussions, it can be found that the CZTSSe material indeed possesses more serious atomic disorder and band tail states compared with other semiconductors. A previous summary of the Urbach energy $\left(E_{\mathrm{U}}\right)$ of the CZTSSe and other materials clearly shows this fact $[41,88-90] . E_{\mathrm{U}}$ is also a featured parameter reflecting the band tail states. As seen in Fig. 8c, at the same bandgap, the CZTSSe exhibits a much higher $E_{\mathrm{U}}$. However, these serious band tail states seem not to be the origin for the large $V_{\mathrm{OC}}$ loss of the CZTSSe solar cell. As in Fig. 8d, even under the same $E_{U}$, the CZTSSe cell still 
gives a much larger $V_{\mathrm{OC}}$ loss than other devices. These results imply that there should be another hidden mechanism limiting the device voltage and that there is an unknown correlation between the atomic disorder and the large voltage loss of the CZTSSe solar cell.

\section{DEEP DEFECTS}

\section{Effective non-radiative recombination centers (NRRCs)}

As mentioned above, the high $V_{\mathrm{OC}}$ deficit of CZTSSe solar cell should stem from rapid non-radiative recombination, as reflected by the extremely short minority carrier lifetime observed in experiments. The CZTSSe exhibited a carrier lifetime of only few nanoseconds ( ns), far less than that of CIGS (>100 ns) [91-93]. It is of great significance to explore and regulate the non-radiative recombination centers (NRRCs) in CZTSSe for promoting the device efficiency. The non-radiative recombination is a process in which an NRRC captures an electron from the CBM and a hole from the VBM, while releasing phonons. The NRRC is mainly the defected electronic state in the forbidden band located in the bulk or at the surface/interface of the semiconductor device. According to the Shockley-Read-Hall theory, deep defects play a dominant role in causing the recombination because of its large overlap with the Fermi energy level [94,95]. Nonetheless, whether a deep defect could act as an effective NRRC still depends on its carrier capture cross-section $(\sigma)$. As a p-type semiconductor, the minority carrier of CZTSSe is electron, and its maximum lifetime can be determined from defect concentration $N_{\mathrm{t}}$ and electron capture cross-section $\left(\sigma_{\mathrm{n}}\right)$, that is

$\tau_{\mathrm{n}}=\frac{1}{v_{\mathrm{th}} \sigma_{\mathrm{n}} N_{\mathrm{t}}}$,

where $v_{\text {th }}$ is the thermal velocity of the CZTSSe determined by the carrier effective mass. It is reported that the $\sigma_{\mathrm{n}}$ highly depends on the energy barrier of the nonradiative electronic state transition $\left(E_{\mathrm{b}}\right)$, while the $E_{\mathrm{b}}$ is closely associated to the lattice relaxation process according to the Huang-Rhys theory [96-99], that is

$E_{\mathrm{b}}=\frac{\left(\Delta E-E_{\mathrm{rel}}\right)^{2}}{4 E_{\mathrm{rel}}}$

$E_{\mathrm{rel}}=\sum_{k} \frac{1}{2} \omega_{k}^{2} \Delta Q_{k}^{2}$.

The lattice relaxation energy $\left(E_{\text {rel }}\right)$ is determined by the frequency of the defect correlated phonon modes $\left(\omega_{k}\right)$ and the coordination difference between the initial and final states $\left(\Delta Q_{k}\right)$. The phonon frequency $\omega_{k}$ is strongly correlated with the strength of the chemical bonds around the defect. Once acquiring both the phonon frequencies and the coordination change, one can calculate $E_{\text {rel }}$ and $E_{\mathrm{b}}$, and thus determine whether the defect is an effective NRRC or not.

\section{Deep defects in CZTSSe}

As shown in Fig. 9, there is a variety of point defects in multiternary CZTS and CZTSe materials. $\mathrm{Cu}$ vacancy $\left(\mathrm{V}_{\mathrm{Cu}}\right.$, acceptor), $\mathrm{Cu}-\mathrm{Zn}$ substitutions $\left(\mathrm{Cu}_{\mathrm{Zn}}\right.$ accepter or $\mathrm{Zn}_{\mathrm{Cu}}$ donor) are shallow defects, and others, including $\mathrm{Cu}_{\mathrm{Sn}}, \mathrm{Zn}_{\mathrm{Sn}}, \mathrm{V}_{\mathrm{Zn}}$, and $\mathrm{V}_{\mathrm{Sn}}$ acceptors, $\mathrm{Sn}_{\mathrm{Cu}}, \mathrm{Sn}_{\mathrm{Zn}}, \mathrm{Zn}_{\mathrm{i}}, \mathrm{V}_{\mathrm{S}}$, and $\mathrm{V}_{\mathrm{Se}}$ donors, are all deep defects [37]. Chen et al. [37] made a systematical calculation on the energy levels and formation energy of these defects. However, few reports have been presented on their carrier capture cross-section. It is a great challenge to evaluate the carrier capture cross-section of these defects from experimental measurements or theoretical calculations. Experimentally, many deep defects coexist and interact with each other, resulting in giant difficulty in determining and analyzing a specific defect. The defect energy levels measured in experiments were generally around $100 \mathrm{meV}$; the deep defect levels were rarely observed. Due to the complexity of the CZTSSe system, only a few theoretical studies have been done to investigate the carrier capture cross-section
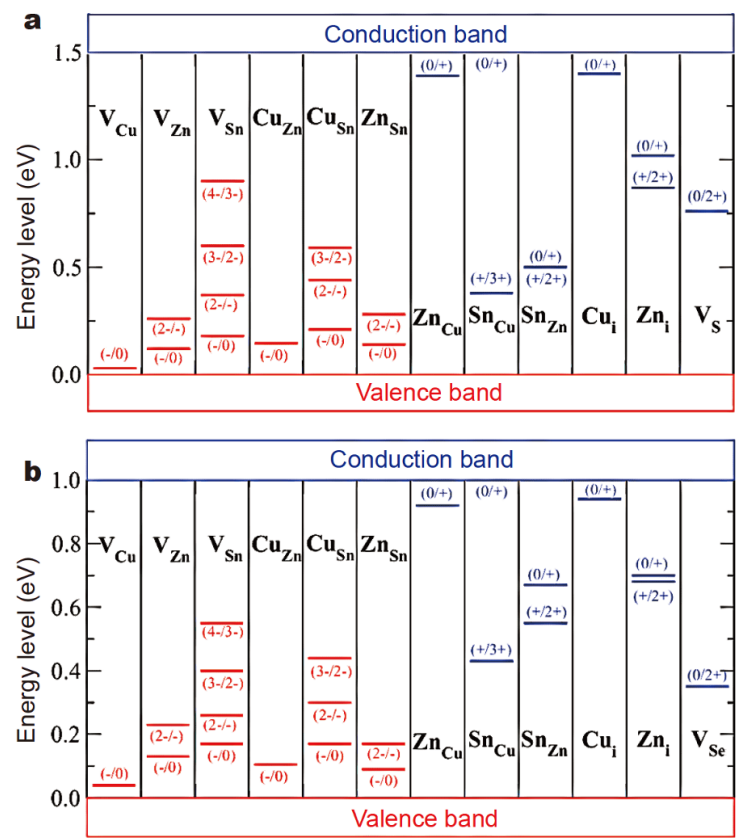

Figure 9 The ionization levels of intrinsic defects in the bandgaps of (a) CZTS and (b) CZTSe. The red bars show the acceptor levels and the blue bars show the donor levels, with the initial and final charge states labeled in parentheses. Reprinted with permission from Ref. [37]. Copyright 2013, Wiley-VCH. 
and the non-radiative recombination mechanism of several certain deep defects.

Li et al. [42] theoretically compared the electron capture capabilities of three deep defects (i.e., $\mathrm{Sn}_{\mathrm{Zn}}{ }^{2+}, \mathrm{Sn}_{\mathrm{Zn}}{ }^{+}$, and $\left.\left[\mathrm{Cu}_{\mathrm{Zn}}-\mathrm{Sn}_{\mathrm{Zn}}\right]^{+}\right)$in CZTS and found that the strength of $\mathrm{Sn}-\mathrm{S}$ bonds around the defect has a significant effect on the carrier capture cross-section. At $300 \mathrm{~K}$, the electron capture cross-section $\left(\sigma_{\mathrm{n}}\right)$ of $\mathrm{Sn}_{\mathrm{Zn}}{ }^{2+}, \mathrm{Sn}_{\mathrm{Zn}}{ }^{+}$, and $\left[\mathrm{Cu}_{\mathrm{Zn}}\right.$ $\left.-\mathrm{Sn}_{\mathrm{Zn}}\right]^{+}$were estimated to be $8.8 \times 10^{-14}, 4.7 \times 10^{-18}$ and $4.5 \times 10^{-14} \mathrm{~cm}^{2}$, respectively. $\mathrm{Sn}_{\mathrm{Zn}}{ }^{2+}$ and $\left[\mathrm{Cu}_{\mathrm{Zn}}-\mathrm{Sn}_{\mathrm{Zn}}\right]^{+}$can be considered as effective NRRCs. Further calculations showed that $\mathrm{Sn}_{\mathrm{Zn}}{ }^{2+}(2+/+)$ and $\left[\mathrm{Cu}_{\mathrm{Zn}}-\mathrm{Sn}_{\mathrm{Zn}}\right]^{+}(+/ 0)$ have relatively larger lattice relaxation energies $E_{\text {rel }}(0.50$, $0.52 \mathrm{eV})$, thus resulting in a small $E_{\mathrm{b}}(0.01,0.02 \mathrm{eV})$, which makes them easier to capture electron. Comparatively, $\mathrm{Sn}_{\mathrm{Zn}}{ }^{+}(+/ 0)$ exhibits a relatively small $E_{\text {rel }}\left(\mathrm{Sn}_{\mathrm{Zn}}{ }^{+}\right)$of $0.23 \mathrm{eV}$ and thus a large $E_{\mathrm{b}}\left(\mathrm{Sn}_{\mathrm{Zn}}{ }^{+}\right)$of $0.44 \mathrm{eV}$. The coordinate diagram for $\mathrm{Sn}_{\mathrm{Zn}}{ }^{2+}(2+/+)$ and $\mathrm{Sn}_{\mathrm{Zn}}{ }^{+}(+/ 0)$ are plotted in Fig. 10a-c. Li et al. [42] explored deeply into these results. Due to the differences in size and charge number between the substitutional and the original atoms, the lattice around the antisite defect is distorted. Every $S n$ atom in these three antisite defects coordinates with four $\mathrm{S}$ atoms, and lattice distortion occurs when $\mathrm{S}$ atoms relax towards or away from the defects. As shown in Fig. $10 \mathrm{~d}-\mathrm{f}$, for $\mathrm{Sn}_{\mathrm{Zn}}{ }^{2+}$ and $\left[\mathrm{Cu}_{\mathrm{Zn}}-\mathrm{Sn}_{\mathrm{Zn}}\right]^{+}$, the $\mathrm{Sn}-\mathrm{S}$ bonds become shorter and stronger because the $\mathrm{S}$ atoms relax towards the $\mathrm{Sn}$ atom, corresponding to high-frequency vibration phonons. According to Equations (6) and (7), it can be inferred that they have larger $E_{\text {rel }}$ and smaller $E_{\mathrm{b}}$. In contrast, the $\mathrm{Sn}-\mathrm{S}$ bond near $\mathrm{Sn}_{\mathrm{Zn}}{ }^{+}$becomes longer and softer, and thus its carrier capture cross-section becomes much smaller. This work provides a theoretical way to evaluate whether a deep defect is an effective NRRC. Nonetheless, it is still difficult to operate this evaluation in complex situations where multiple defects may interact with each other.

Kim et al. [100] proposed that the rapid carrier recombination through NRRCs is closely related to the $\left(5 \mathrm{~s}^{2}\right)$ lone pair electronic state of Sn. At first, it was shown that
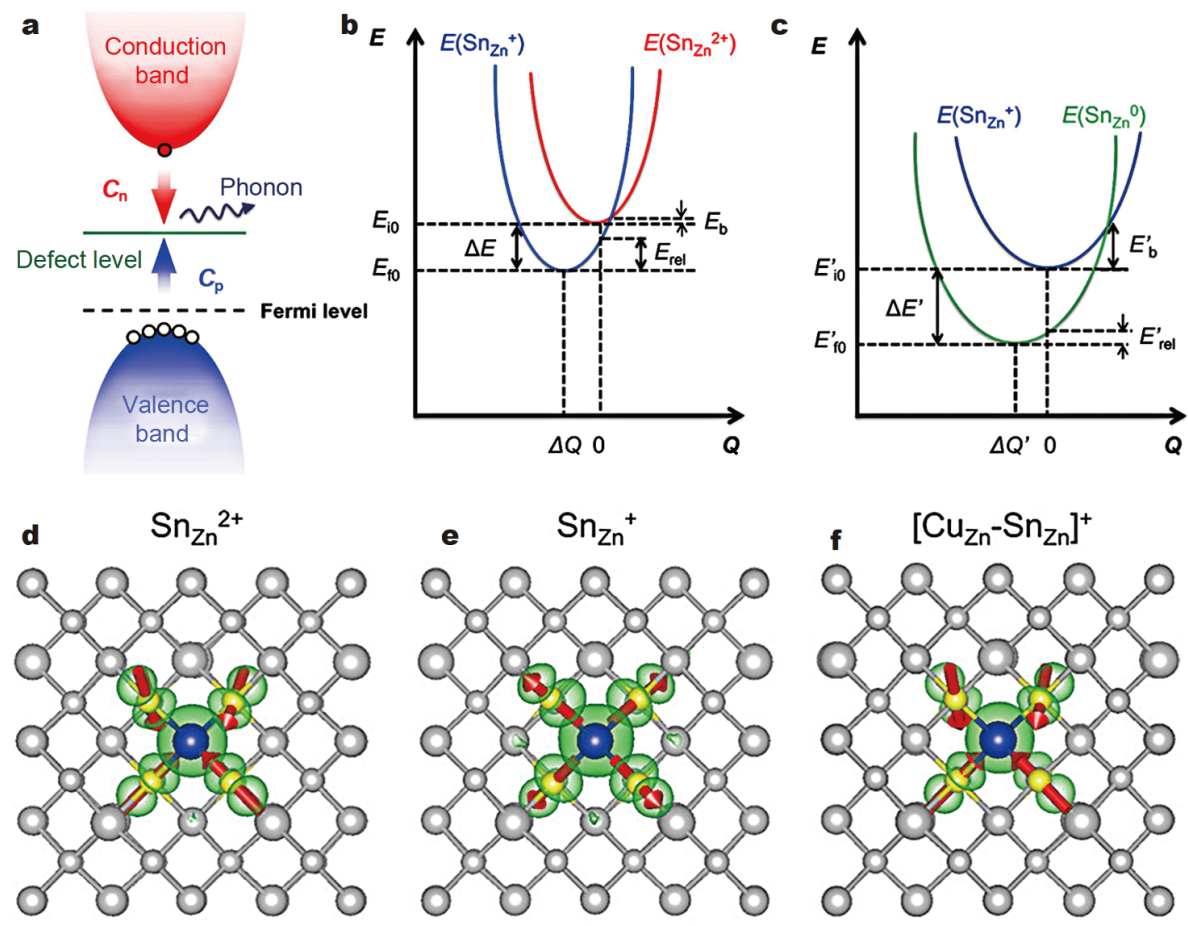

Figure 10 (a) Schematic diagram of non-radiative recombination induced by deep defect. Configuration coordinate diagram (under the harmonic approximation) of the non-radiative electronic state transition for (b) $\mathrm{Sn}_{\mathrm{Zn}}{ }^{2+}$ capturing an electron and converting to $\mathrm{Sn}_{\mathrm{Zn}}{ }^{+}$and (c) $\mathrm{Sn}_{\mathrm{Zn}}{ }^{+}$capturing an electron and converting to neutral $\mathrm{Sn}_{\mathrm{Zn}}{ }^{0}$. The non-radiative electronic state transition mainly occurs at the cross point of energy curves, it is necessary for a system to overcome energy barrier $E_{\mathrm{b}}$ with the help of phonon. $\Delta E=E_{\mathrm{i} 0}-E_{\mathrm{f} 0}$ is the electronic energy difference at the equilibrium states, and $\Delta Q$ corresponds to the difference in the equilibrium coordinates between the initial and final states. Lattice relaxation energy, $E_{\text {rel }}$, originates from the equilibrium configuration coordinate difference between the initial and final states. The phonon modes and the electronic states induced by the defects (d) $\mathrm{Sn}_{\mathrm{Zn}}{ }^{2+}$, (e) $\mathrm{Sn}_{\mathrm{Zn}}{ }^{+}$, and (f) $\left[\mathrm{Cu}_{\mathrm{Zn}}-\mathrm{Sn}_{\mathrm{Zn}}\right]^{+}$. The green isosurfaces represent the squared norms of wavefunctions of the transition energy levels of defects, whereas the red arrows denote the vibration of the $\mathrm{S}$ atoms (marked in yellow) around the $\mathrm{Sn}_{\mathrm{Zn}}$ antisite (marked in blue) associated with the defect-induce phonon modes. Reprinted with permission from Ref. [42]. Copyright 2019, ACS publishing. 
the sulfur vacancy $\left(\mathrm{V}_{\mathrm{S}}\right)$ can be an effective NRRC through the aid of an intermediate excited state where electron is captured by $S n$ [43]. When Sn(IV) near a neutral $V_{S}$ captures an electron, the $\operatorname{Sn}(\mathrm{IV})$ is reduced to a metastable $\mathrm{Sn}(\mathrm{III})$ and $\mathrm{V}_{\mathrm{S}}{ }^{0}$ becomes $\mathrm{V}_{\mathrm{S}}^{+}$. The unoccupied level of $\mathrm{V}_{\mathrm{S}}{ }^{+}$is close to the VBM of CZTS and thus it can capture a hole under illumination and turns into $\mathrm{V}_{\mathrm{S}}^{2+}$. The hole capturing promotes the $\mathrm{V}_{\mathrm{S}}{ }^{2+}$ energy level close to the CBM of CZTS. $\mathrm{V}_{\mathrm{S}}^{2+}$ can efficiently capture an electron and recover the +1 charge state, thus completing the electron-hole non-radiative recombination process. Furthermore, $\mathrm{V}_{\mathrm{S}},\left[\mathrm{V}_{\mathrm{S}}+\mathrm{Cu}_{\mathrm{Zn}}\right], \mathrm{Sn}_{\mathrm{Zn}}$ under S-poor conditions and $\mathrm{Sn}_{\mathrm{Zn}}$ under $\mathrm{S}$-rich conditions have also been investigated. They were all proved to be effective NRRCs, limiting the minority carrier lifetime, and all of them are associated with $\mathrm{Sn} 5 \mathrm{~s}^{2}$ lone-pair state. In CZTS, the formation of an inert lone pair $\left(5 \mathrm{~s}^{2}\right)$ reduces the oxidation state of $\mathrm{Sn}$ from +4 to +2 . Due to the difference in ionic radii between $S n(I I)$ and $S n(I V)$, large lattice distortions around the lone-pair defect centers were found. The high stability of the lone pair suppresses the ionization of certain point defects and induces deep carrier transition level in the bandgap. Therefore, the lone-pair effect associated with $\mathrm{Sn}$ is responsible for both the deep defect levels and large lattice distortions in CZTS, thereby resulting in rapid electron-hole non-radiative recombination.

These reported studies have highlighted a connection between the $S n$ atom and the effective NRRCs. A number of experimental studies have also shown that the CZTSSe solar cell efficiency is very sensitive to the $\mathrm{Sn}$ composition $[52,101,102]$. However, the details of the effects of Sn composition on specific deep defects are rarely reported. Compared with the $\mathrm{Cu} / \mathrm{Zn}$ disorder, studies on deep defects of CZTSSe are relatively lacking, and most of reported results are based on theoretical calculations. The experimental characterization or regulation is still difficult to realize at present, which should be regarded as an important direction for the development of CZTSSe.

\section{Synergy effect}

Considering the complexity of CZTSSe material structures and the diversity of defect types, the $V_{\mathrm{OC}}$ deficit of the CZTSSe cell may not be caused by a single type of defect. Considering a perfectly crystalline CZTSSe absorber without any undesirable defects in the solar cell (Fig. 11a), it absorbs incident photons to generate free carriers. The free electrons diffused into the depletion region are extracted by the n-type material, and the free holes diffused to the back side are collected by the back electrode. The perfect crystal has a very low probability of carrier recombination, thus the free carriers have a long lifetime and a long diffusion length, which will lead to a high $V_{\mathrm{OC}}$. When the band tail states (induced by $\mathrm{Cu} / \mathrm{Zn}$ disorder) are formed at the band edge of the absorber semiconductor, the effective $E_{\mathrm{g}}$ of the absorber is slightly reduced. In addition, some free carriers will be trapped in the band tail states and thus decreasing the $V_{\mathrm{OC}}$ of the solar cell (Fig. 11b). Nonetheless, this decrease may be much smaller than the experimental result, as predicted by Equation (4). The deep defects can further decrease the $V_{\mathrm{OC}}$ by accelerating the non-radiative recombination processes. Although it was experimentally found that the CZTSSe possessed an ultra-short carrier lifetime, the contribution of the deep defects has not been confirmed until now in experiments. In this case, we prefer to propose that there is a synergy effect between the shallow and deep traps in causing the charge loss of the cell, as shown in Fig. 11c. Compared with the deep defect, the shallow defect usually has much smaller energy barrier of carrier capturing and the carrier trapping can be completed within a picosecond timescale. For the deep defect, carrier capturing from the shallow defect may be much easier than from the continuum band. In addition, the carrier exchange between the tail states and the continuum band could significantly decrease the carrier mobility and thus
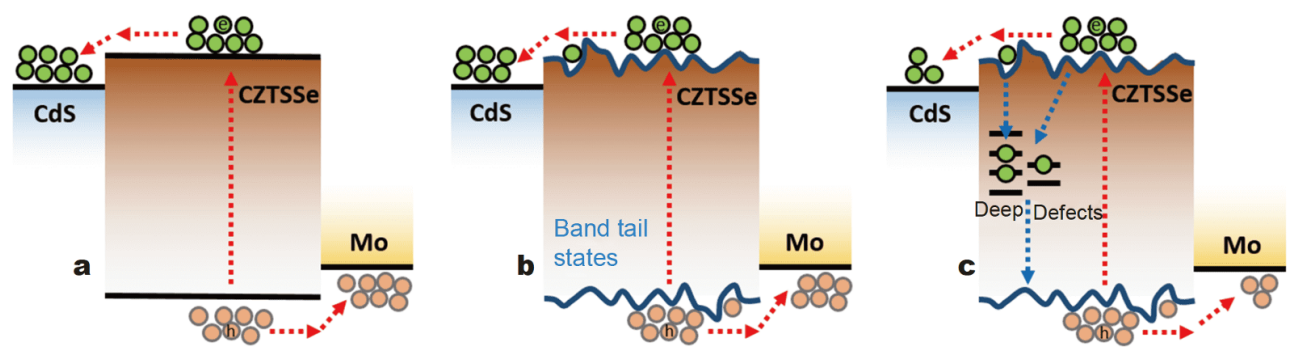

Figure 11 Schematic diagrams of the charge processes in solar cells prepared with (a) perfect CZTSSe absorber without any undesirable defects, (b) CZTSSe absorber only with $\mathrm{Cu} / \mathrm{Zn}$ disorder, and (c) CZTSSe absorber with $\mathrm{Cu} / \mathrm{Zn}$ disorder and deep defects. 
slow down the carrier transport. This will give the deep defect more time and opportunity to capture carriers that transport around it.

\section{EXPERIMENTAL IDENTIFICATION AND CONTROL OF DEFECTS}

\section{Experimental identification of defects}

There are so many kinds of defects in CZTSSe materials, and different defects have different influence mechanisms on the solar cell performance, which requires us to characterize and control specific defects, especially the killer defects. Several experimental characterization methods for semiconductor defects have been used in the CZTSSe field, and four methods will be discussed here, that is, deep level transient spectroscopy (DLTS), thermal admittance spectroscopy (TAS), temperature-dependent PL spectroscopy (TPL), and transient photocapacitance spectroscopy (TPC). The defect information of CZTSSe materials obtained by these methods is listed in Table 2 .

DLTS is one of the most useful methods to detect deep defects of a semiconductor, which can measure the activation energy, concentration, electron- or hole-capture cross-section of each defect $[103,104]$. This method comes from the concept of p-n junction capacitance transients due to the filling and emptying of defects at fixed temperatures. The sign of the capacitance-mode DLTS (C-DLTS) signal peak can help determine whether the deep defect is a minority carrier trap or a majority carrier trap. The height of the DLTS signal peak is proportional to the defect concentration, and the position of the peak is determined by the thermal emission rate of the defect. The Arrhenius curve of corresponding DLTS peak is $\ln \left(e_{\mathrm{n}, \mathrm{p}} / T^{2}\right) v s .1 / T$, where $e_{\mathrm{n}, \mathrm{p}}$ is the carrier emission rate of the defect. By linearly fitting the Arrhenius curve, the defect activation energy $\left(E_{\mathrm{a}}\right)$ can be calculated from the slope, and the carrier capture cross-section $\left(\sigma_{\mathrm{n}, \mathrm{p}}\right)$ of the defect can be calculated from the intercept, that is

$e_{\mathrm{n}, \mathrm{p}}(T)=\gamma \sigma_{\mathrm{n}, \mathrm{p}} T^{2} \exp \left(-\frac{E_{\mathrm{a}}}{k T}\right)$,

where $\gamma$ is a constant for a given material. Das et al. [105] used the current-mode DLTS (I-DLTS) to analyze two CZTSSe solar cells (Fig. 12a-c). The pure CZTSe cell, with an efficiency of $7.1 \%$, showed only a shallow $\mathrm{V}_{\mathrm{Cu}}$ level at $E_{\mathrm{v}}+0.03 \mathrm{eV}$, whereas the CZTSSe $(\mathrm{S} / \mathrm{Se}=1.4)$ cell, with an efficiency of $4.1 \%$, showed two dominant deep acceptor levels at $E_{\mathrm{v}}+0.12 \mathrm{eV}$ and $E_{\mathrm{v}}+0.32 \mathrm{eV}$ corresponding to $\mathrm{Cu}_{\mathrm{Zn}}$ and $\mathrm{Cu}_{\mathrm{Sn}}$ antisites. The result of the pure CZTSe cell indicates that although $\mathrm{Cu}_{\mathrm{Zn}}$ has a lower formation energy, $\mathrm{V}_{\mathrm{Cu}}$ may be the predominant lattice defect in kesterite. However, the efficiency of the CZTSe device with only benign defect is still low. Qi et al. [106] also detected $\mathrm{Cu}_{\mathrm{Zn}}$ and $\mathrm{Cu}_{\mathrm{Sn}}$ defects by conventional CDLTS, with the $E_{\mathrm{a}}$ of 175 and $366 \mathrm{meV}$, respectively. Campbell et al. [107] calculated the $E_{\mathrm{a} 1}$ to be $86 \pm 7 \mathrm{meV}$ according to a broad DLTS peak at around $115 \mathrm{~K}$ (Fig. 12d and e). They thought the observed peak may in fact be comprised of a distribution of deep levels closely spaced in energy, and tried to separate those levels via a Laplace analysis method but failed. Thus this peak was vaguely identified as $\mathrm{Cu}_{\mathrm{Zn}}$ antisite. They also observed an energy level of $E_{\mathrm{a} 2}=167 \pm 10 \mathrm{meV}$ (Fig. 12d and e), which was considered as a Sn-related defect, and finally identified as $\mathrm{Zn}_{\mathrm{Sn}}$ according to the $\mathrm{Cu}$-poor and $\mathrm{Zn}$-rich composition condition. Besides, other shallower defects beyond the scope of DLTS were detected by TPL, which will be mentioned below. In the meantime, Campbell et al. [107] acquired the minority carrier lifetime (0.20 ns) and minority carrier diffusion length $(203 \mathrm{~nm})$ of the CZTSSe film by relevant photoelectric measurement and analysis. We can see from these different reports that there is still no convincing understanding on the defects because the experimental identification of defects has strong subjectivity. In different studies, similar energy levels, measured by the same method on the samples with nearly identical bandgap, have been regarded to be corresponding to different defects.

According to the reported information, such as the density and the carrier capture cross-section of the defects, measured by DLTS, here we can estimate the shortest carrier lifetime of CZTSSe by Equation (5). The calculated carrier lifetimes $\tau_{\mathrm{c}}$ are listed in Table 2 $[89,90,101,105-112]$. Unexpectedly, the $\tau_{c}$ values derived from the DLTS are in the order of microsecond or even millisecond, which is several orders of magnitude larger than the measured result $\left(\tau_{\mathrm{m}}\right)$. As shown in Fig. 12f, the $\tau_{\mathrm{m}}$ values measured by time-resolved PL (TRPL) are mainly in the range of $\sim 1$ to $\sim 10 \mathrm{~ns}$ for the CZTSSe solar cells with efficiencies of $9 \%-11 \%$ [91]. Such a large gap suggests that some fundamental properties about CZTSSe materials remain undiscovered. More effective NRRCs may have not been detected for some reasons until now. Possibly, the synergy effect we proposed above has indeed accelerated the non-radiative recombination of the carriers. In our opinion, more new and independent methods are desired to be developed and exploited to probe the defect properties of the CZTSSe and to establish a closer correlation between the defect and the non-radiative recombination. 
Table 2 Defect states information in CZTSSe materials obtained by different test methods

\begin{tabular}{|c|c|c|c|c|c|c|}
\hline Method & Reference & $E_{\mathrm{a}}(\mathrm{meV})$ & $N_{\mathrm{t}}\left(\mathrm{cm}^{-3}\right)$ & $\sigma\left(\mathrm{cm}^{2}\right)$ & $\tau_{\mathrm{c}}(\mu \mathrm{s})$ & Possible defect \\
\hline \multirow[t]{3}{*}{ I-DLTS } & \multirow[t]{3}{*}{ Das et al. [105] } & $30 \pm 10$ & $6.46 \times 10^{15}$ & $2.52 \times 10^{-20}$ & 166 & $\mathrm{~V}_{\mathrm{Cu}}$ \\
\hline & & $120 \pm 40$ & $6.17 \times 10^{14}$ & $1.31 \times 10^{-20}$ & \multirow{2}{*}{28} & $\mathrm{Cu}_{\mathrm{Zn}}$ \\
\hline & & $320 \pm 60$ & $6.73 \times 10^{14}$ & $2.04 \times 10^{-18}$ & & $\mathrm{Cu}_{\mathrm{Sn}}$ \\
\hline \multirow[t]{4}{*}{ C-DLTS } & \multirow[t]{2}{*}{ Qi et al. [106] } & 175 & $6.69 \times 10^{14}$ & $1.06 \times 10^{-21}$ & \multirow{2}{*}{6.98} & $\mathrm{Cu}_{\mathrm{Zn}}$ \\
\hline & & 366 & $9.46 \times 10^{14}$ & $4.10 \times 10^{-18}$ & & $\mathrm{Cu}_{\mathrm{Sn}}$ \\
\hline & \multirow[t]{2}{*}{ Campbell et al. [107] } & $86 \pm 7$ & $(1.70 \pm 0.22) \times 10^{14}$ & $(1.08 \pm 0.95) \times 10^{-20}$ & \multirow{2}{*}{10690} & $\mathrm{Cu}_{\mathrm{Zn}}$ \\
\hline & & $167 \pm 10$ & $(3.17 \pm 0.32) \times 10^{13}$ & $(2.20 \pm 1.99) \times 10^{-20}$ & & $\mathrm{Zn}_{\mathrm{Sn}}$ \\
\hline \multirow[t]{8}{*}{ TAS } & \multirow[t]{2}{*}{ Fernandes et al. [108] } & $44.7 \pm 0.7$ & - & - & - & $\mathrm{V}_{\mathrm{Cu}}$ \\
\hline & & $112.7 \pm 3.5$ & - & - & - & $\mathrm{Cu}_{\mathrm{Zn}}$ \\
\hline & Gunawan et al. [109] & $130-200^{\mathrm{a}}$ & - & - & - & $\mathrm{Cu}_{\mathrm{Zn}}$ \\
\hline & \multirow[t]{3}{*}{ Duan et al. [110] } & 134 & $4.96 \times 10^{15}$ & $5.20 \times 10^{-17 b}$ & 0.1 & $\mathrm{Cu}_{\mathrm{Zn}}$ \\
\hline & & 163 & $5.24 \times 10^{15}$ & $1.56 \times 10^{-17 b}$ & 0.47 & $\mathrm{Cu}_{\mathrm{Zn}}$ \\
\hline & & 183 & $1.14 \times 10^{16}$ & $8.00 \times 10^{-18 b}$ & 0.42 & $\mathrm{Cu}_{\mathrm{Zn}}$ \\
\hline & \multirow[t]{2}{*}{ Larramona et al. [101] } & $120-170^{c}$ & - & - & - & $\mathrm{Cu}_{\mathrm{Zn}}$ \\
\hline & & $600 \pm 100$ & - & - & - & $\mathrm{V}_{\mathrm{Sn}}$ or $\mathrm{Cu}_{\mathrm{Sn}}$ \\
\hline \multirow[t]{9}{*}{ TPL } & \multirow[t]{2}{*}{ Larramona et al. [101] } & $25-30^{c}$ & - & - & - & Potential fluctuation \\
\hline & & $120-130^{c}$ & - & - & - & Donor \\
\hline & \multirow[t]{2}{*}{ Luckert et al. [111] } & $7 \pm 2$ & - & - & - & Donor \\
\hline & & $27 \pm 3$ & - & - & - & Acceptor \\
\hline & \multirow[t]{2}{*}{ Grossberg et al. [112] } & $277 \pm 6$ & - & - & - & \multirow{2}{*}{$\mathrm{Cu}_{\mathrm{Sn}}$ or $\mathrm{Zn}_{\mathrm{Sn}}$} \\
\hline & & $289 \pm 7$ & - & - & - & \\
\hline & \multirow[t]{2}{*}{ Campbell et al. [107] } & $38.3 \pm 3.8$ & \multirow{2}{*}{$2.1 \times 10^{18 \mathrm{~d}}$} & - & - & $\mathrm{V}_{\mathrm{Cu}}$ \\
\hline & & $3.2 \pm 0.5$ & & - & - & $\mathrm{Sn}_{\mathrm{Cu}}$ \\
\hline & & \multicolumn{5}{|c|}{ Measurement results } \\
\hline \multirow[t]{4}{*}{ TPC } & \multirow[t]{2}{*}{ Miller et al. [89] } & \multicolumn{5}{|c|}{$1.0 \mathrm{eV} \leq E_{\mathrm{g}} \leq 1.2 \mathrm{eV}: E_{\mathrm{U}} \leq 18 \mathrm{meV} ; E_{\mathrm{t}}=E_{\mathrm{v}}+800 \mathrm{meV}$} \\
\hline & & \multicolumn{5}{|c|}{$1.4 \mathrm{eV} \leq E_{\mathrm{g}} \leq 1.5 \mathrm{eV}: E_{\mathrm{U}}=25-30 \mathrm{meV} ; E_{\mathrm{t}}=E_{\mathrm{v}}+800 \mathrm{meV}$} \\
\hline & \multirow[t]{2}{*}{ Islam et al. [90] } & \multicolumn{5}{|c|}{$\mathrm{S} /(\mathrm{S}+\mathrm{Se})=0.15: E_{\mathrm{U}}=54 \mathrm{meV} ; E_{\mathrm{t}}=E_{\mathrm{v}}+1000 \mathrm{meV}$} \\
\hline & & \multicolumn{5}{|c|}{$\mathrm{S} /(\mathrm{S}+\mathrm{Se})=0: E_{\mathrm{U}}=69 \mathrm{meV} ; E_{\mathrm{t}}=E_{\mathrm{v}}+1000 \mathrm{meV}$} \\
\hline
\end{tabular}

a) The different $E_{\mathrm{a}}$ values in this range are for CZTSSe films with various bandgaps; b) the $\sigma$ values are estimated from the Arrhenius curves in Ref. [110]; c) the different $E_{\mathrm{a}}$ values in these ranges are for CZTSSe films with various Sn additions; d) the total density of the two shallow defects was calculated from the PL peak blue-shift value in excitation-dependent PL spectra.

TAS is also widely used in CZTSSe to detect deep defects [113]. The Arrhenius relationship of TAS exists between $\ln \left(\omega_{0} / T^{2}\right)$ and $1 / T$ [114], where $\omega_{0}$ is a characteristic frequency for capacitance transition. Fernandes et al. [108] successfully fitted the complex admittance plane with an expanded equivalent circuit (Fig. 13a and b), in which two recombination centers $\left(C_{1}-R_{1}, C_{2}-R_{2}\right)$ were considered [108]. The characteristic frequency was defined as $\omega_{0}=1 /\left(R_{i} C_{i}\right), i=1,2$. Through temperaturedependent measurements, two defect levels were detected, that is, $E_{\mathrm{a} 1}=44.7 \pm 0.7 \mathrm{meV}$ for $\mathrm{V}_{\mathrm{Cu}}$, and $E_{\mathrm{a} 2}=112.7 \pm$ $3.5 \mathrm{meV}$ for $\mathrm{Cu}_{\mathrm{Zn}}$ (Fig. 13c). Using TAS, Gunawan et al.
[109] and Duan et al. [110] found that the $E_{\mathrm{a}}$ values (130$200 \mathrm{meV}$ ) of $\mathrm{Cu}_{\mathrm{Zn}}$ defect tended to increase with higher $\mathrm{S} /$ $(\mathrm{S}+\mathrm{Se})$ ratio in CZTSSe alloys (Fig. 14a and b). Gunawan et al. [109] thought the reason might be the concomitant decrease in the dielectric constant or in the crystal lattice constant when increasing anion substitution from Se to $S$ (Fig. 14c). Duan et al. [110] thought that the VBM moves down as the $\mathrm{S}$ content increase, potentially yielding defects with higher activation energies. In Enkhbat's recent TAS study [115], the detected activation energy even rose from 59 to $367 \mathrm{meV}$ with S-alloying. This implies that the dominant defect state of the CZTSSe becomes deeper at 

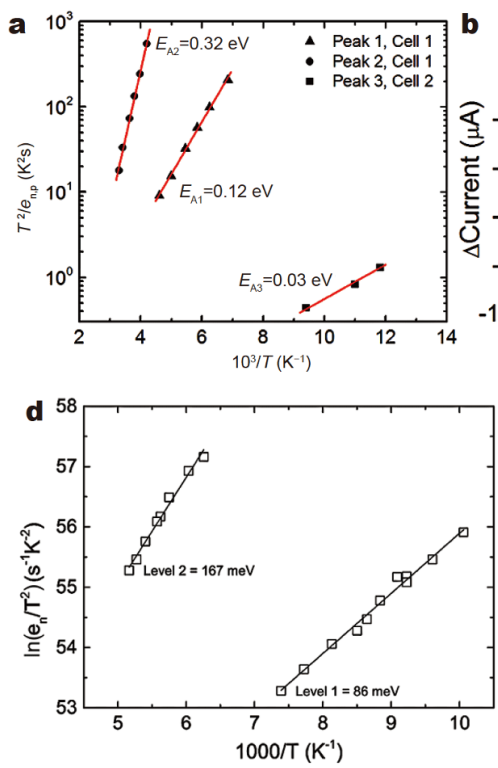
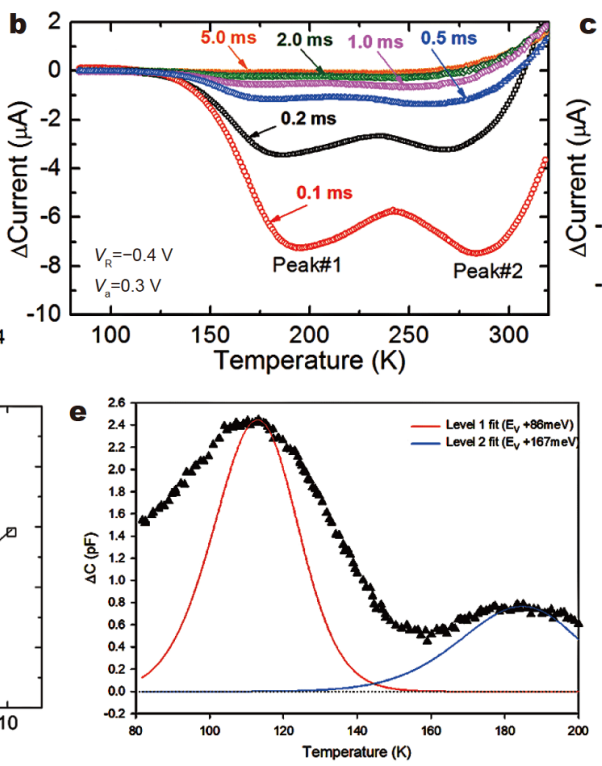
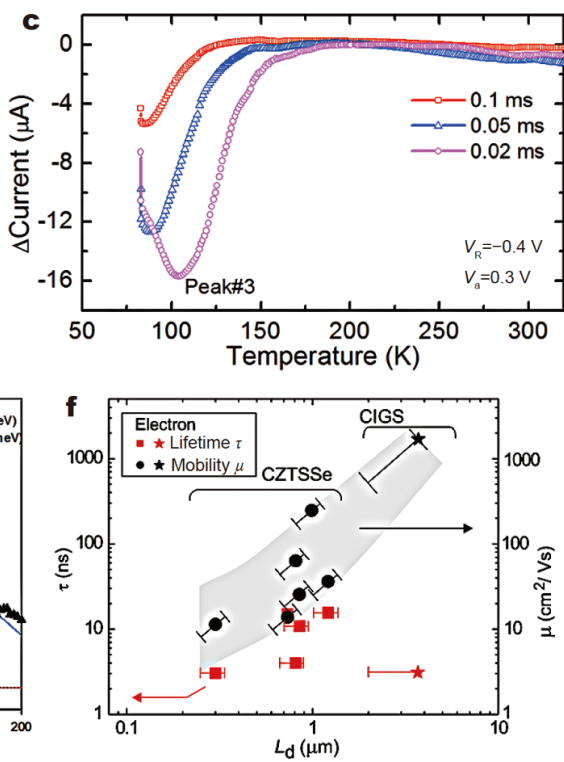

Figure 12 (a) Arrhenius plots corresponding to the peaks from I-DLTS signal of (b) Cell 1 ( $\mathrm{S} / \mathrm{Se}=1.4$ ) and (c) Cell 2 (pure CZTSe) obtained by Das et al. Reprinted with permission from Ref. [105]. Copyright 2014, AIP publishing. (d) Arrhenius plots corresponding to the peaks from (e) C-DLTS signal obtained by Campbell et al. Reprinted with permission from Ref. [107]. Copyright 2019, IOP publishing. (f) Minority carrier lifetime and mobility versus minority carrier diffusion length. Reprinted with permission from Ref. [91]. Copyright 2013, AIP publishing.
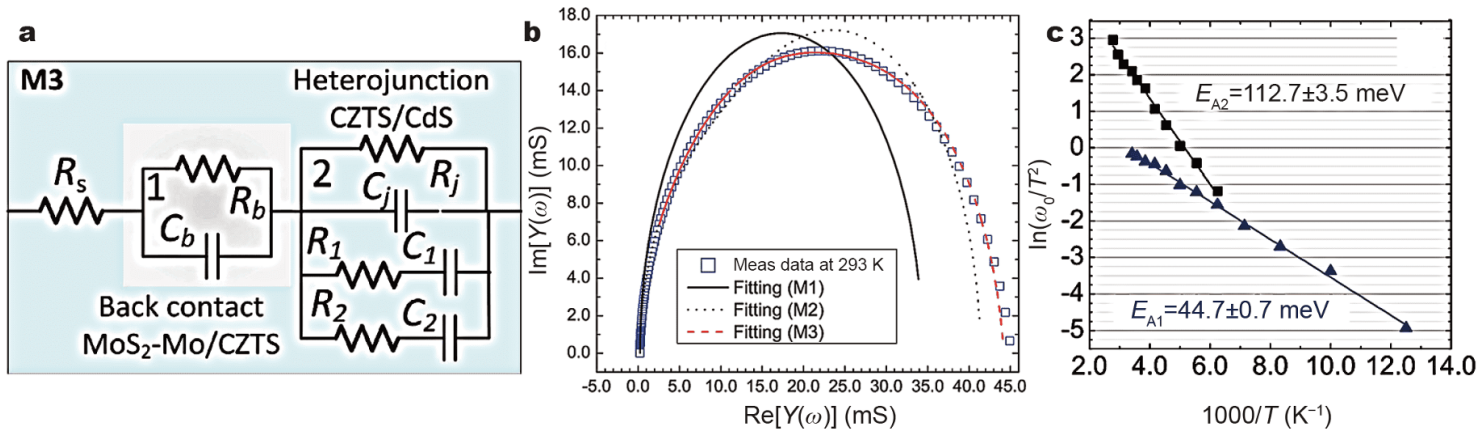

Figure 13 (a) AC response equivalent circuit of CZTS solar cell constructed by Fernandes et al. (b) Complex admittance plane of the studied solar cell measured at $293 \mathrm{~K}$ and the fitting results for the AC response equivalent circuits. (c) Arrhenius plot for the estimation of the defect energies. Reprinted with permission from Ref. [108]. Copyright 2012, AIP publishing.

higher S content. This may explain why high-efficiency CZTSSe solar cells are rarely based on S-rich materials. Larramona et al. [101] detected an ultra-deep defect at $E_{\mathrm{a}}=600 \pm 100 \mathrm{meV}$, and thought it was $\mathrm{V}_{\mathrm{Sn}}$ or $\mathrm{Cu}_{\mathrm{Sn}}$. From the reported TAS results, we can also estimate the shortest carrier recombination lifetimes (Table 2), which are also larger than the $\tau_{\mathrm{m}}$ values measured by TRPL. We need to note that although the shallow defects such as the $\mathrm{Cu}_{\mathrm{Zn}}$ exhibit fast charge capturing, they should not be effective NRRCs because they may not be simultaneously active to both electrons and holes. Nonetheless, these defects may have played a critical role in the synergy process for realizing charge recombination.
TPL was also used to estimate the defect levels. It was generally believed that there is a relationship between the steady-state PL intensity and the temperature [116], that is

$I_{\mathrm{PL}}(T)=I_{0} /\left[1+A_{1} \exp \left(-\frac{E_{\mathrm{a} 1}}{k T}\right)+A_{2} \exp \left(-\frac{E_{\mathrm{a} 2}}{k T}\right)\right]$,

where $I_{0}$ is the intensity at the lowest temperature, $A_{1}$ and $A_{2}$ are fitting parameters. In the original theory, the $E_{\mathrm{a} 1}$ or $E_{\mathrm{a} 2}$ represented the activation energy of PL quenching due to the thermal activated non-radiative charge transition, similar to the $E_{\mathrm{b}}$ in Equation (6). In some studies later, this activation energy was also thought as the defect en- 


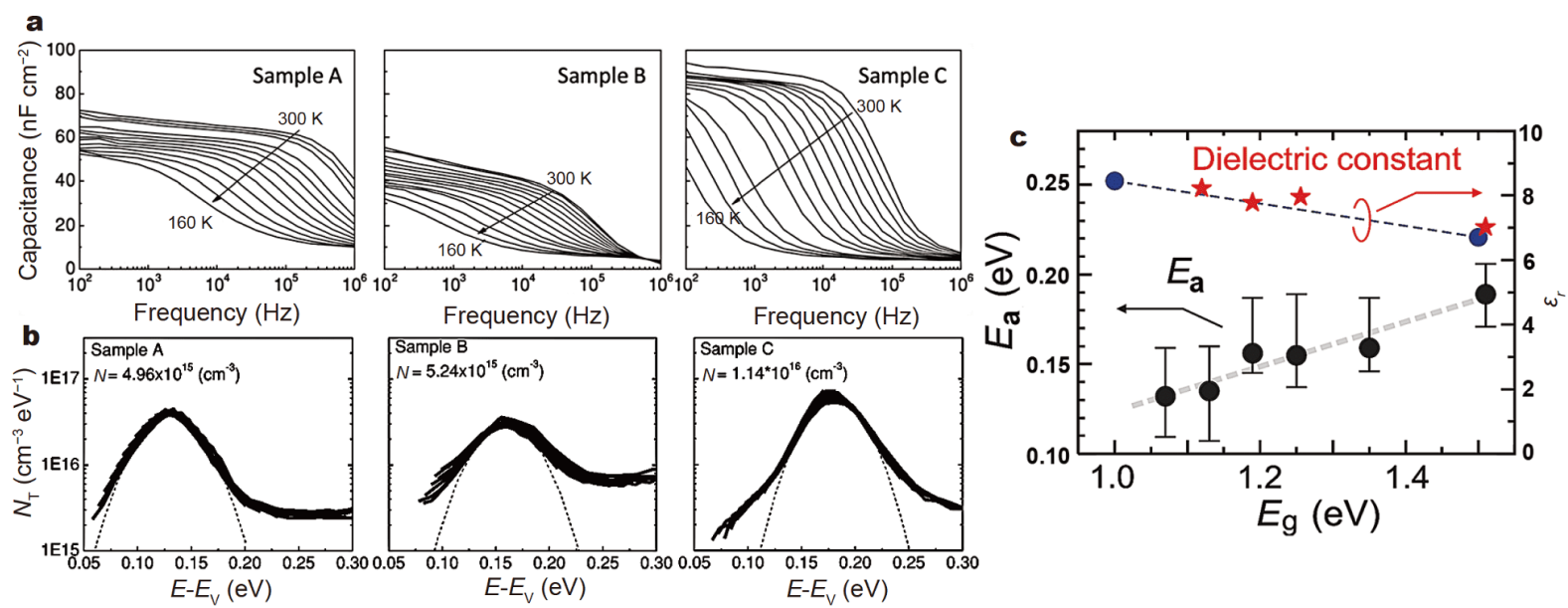

Figure 14 (a) Admittance spectra of devices with various sulfur contents: sample A $(\mathrm{S} /(\mathrm{S}+\mathrm{Se})=0.35)$, sample B $(\mathrm{S} /(\mathrm{S}+\mathrm{Se})=0.8)$, sample C $(\mathrm{S} /(\mathrm{S}+\mathrm{Se})=1)$, measured by Duan et al. (b) Defect spectra derived from admittance spectra in (a). Reprinted with permission from Ref. [110]. Copyright 2013, WileyVCH. (c) Summary of the acceptor levels (dashed line is guide to the eye) and relative dielectric constants determined from the admittance spectra obtained by Gunawan et al. The blue filled circles are the theoretical values of the relative dielectric constants, and the star points are the experimental data. Reprinted with permission from Ref. [109]. Copyright 2012, AIP publishing.

ergy level. Whether this usage is reasonable or not is a question. Nonetheless, we still collect some studies here for the readers' reference. Larramona et al. [101] used TPL to find two defect levels that were not detected by TAS (Fig. 15a and b). One was classified as the potential fluctuation with a smaller energy level $(25-30 \mathrm{meV})$, and the other was considered as a donor defect with its activation energy of $120-130 \mathrm{meV}$. Campbell et al. [107] detected a shallow donor $(3.2 \pm 0.5 \mathrm{meV})$ for $\mathrm{Sn}_{\mathrm{Cu}}$ and a shallow acceptor $(38.3 \pm 3.8 \mathrm{meV})$ for $\mathrm{V}_{\mathrm{Cu}}$, and neither of them had been detected by the DLTS. In addition, Campbell et al. [107] calculated the density of the donoracceptor-pair $\left(\mathrm{Sn}_{\mathrm{Cu}}\right.$ and $\left.\mathrm{V}_{\mathrm{Cu}}\right)$ to be $2.1 \times 10^{18} \mathrm{~cm}^{-3}$ from the blue-shift value of excitation-dependent PL spectra. Luckert et al. [111] studied pure CZTSe, for which two activation energies of $E_{\mathrm{a} 1}=7 \pm 2 \mathrm{meV}$ and $E_{\mathrm{a} 2}=27 \pm 3 \mathrm{meV}$ were determined. Later, Grossberg et al. [112] proposed that the deep defects in pure CZTS were detected by TPL for the first time. Two PL peaks were observed in their study (Fig. 15c), corresponding to similar activation energies of $287 \pm 7$ and $277 \pm 6 \mathrm{meV}$ (Fig. 15d). It was considered that these two peaks arise from the band-toimpurity recombination process involving the same deep acceptor defect $\left(\mathrm{Cu}_{\mathrm{Sn}}\right.$ or $\left.\mathrm{Zn}_{\mathrm{Sn}}\right)$ but the different CZTS phase with different bandgap. Notably, Grossberg et al. [112] abandoned the activation energy derived from the low-temperature regime, whose value was usually a few $\mathrm{meV}$ in other studies. In the low temperature regime, the PL intensity evolution exhibited an approximate $T^{-2}$ de-
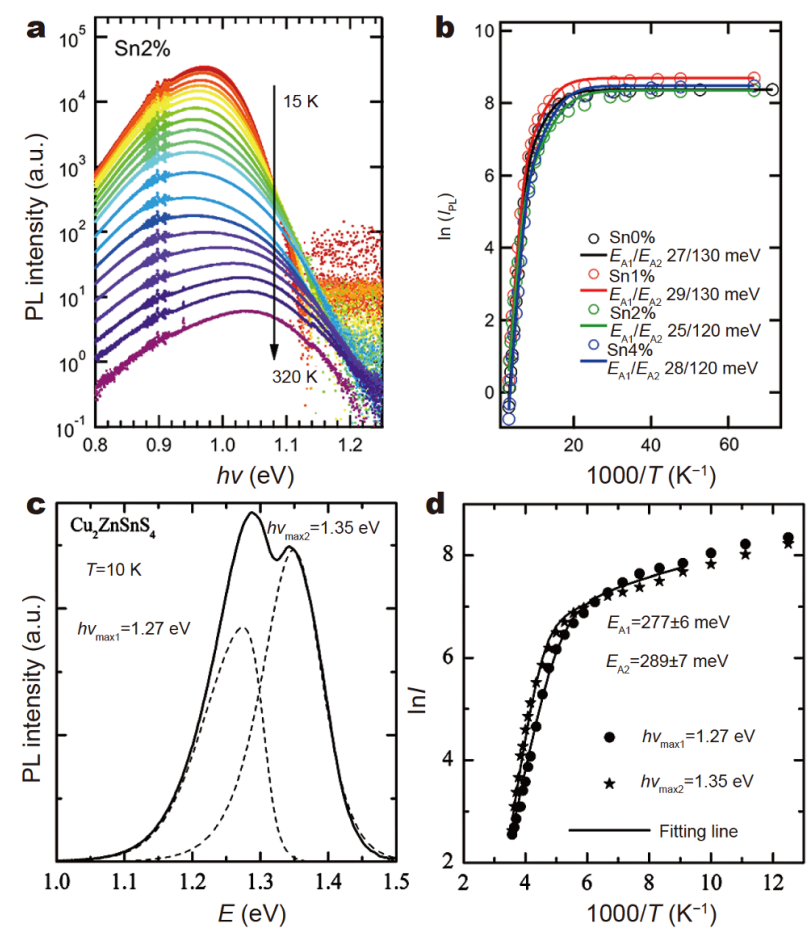

Figure 15 (a) TPL spectra of a CZTSSe film fabricated with $2 \%$ Sn addition. (b) Arrhenius plots of the PL intensity for CZTSSe films with various Sn additions. Reprinted with permission from Ref. [101]. Copyright 2015, Wiley-VCH. (c) Low-temperature PL spectrum of CZTS polycrystals together with the fitting result. (d) Arrhenius plots derived from the temperature-dependent PL spectra of CZTS polycrystals. Reprinted with permission from Ref. [112]. Copyright 2012, AIP publishing. 
pendence, similar to correlation between defect's capture cross-section and temperature [117]. This may indicate that the activation energy obtained from the TPL is not a true defect energy level.

TPC has also been used to study defect state distributions in CZTSSe with various bandgaps [118]. Miller et al. [89] investigated five CZTSSe solar cells with different S/ Se ratios (Fig. 16a and b). The TPC spectra indicated that $E_{U}$ of band tail states was limited within $18 \mathrm{meV}$ when the bandgap was smaller than $1.2 \mathrm{eV}$, whilst $E_{\mathrm{U}}$ was in the range of 25-30 meV for higher-bandgap samples. Besides, a deep defect centered at $E_{\mathrm{v}}+800 \mathrm{meV}$ existed in most samples. Islam et al. [90] measured two samples (Fig. 16c and $\mathrm{d})$, and the $E_{\mathrm{U}}$ values were determined to be 54 and $69 \mathrm{meV}$ for pure CZTS and CZTSSe $(\mathrm{S} /(\mathrm{S}+\mathrm{Se})=0.15)$, respectively. A deep defect centered at around $1.0 \mathrm{eV}$ above the VBM was observed in the CZTS sample.

At present, the experimental measurements of the defects in CZTSSe show that the Urbach energies or the activation energies of the shallow defects increase with the width of the bandgap, while the location of the deep defect seems to remain unchanged, as seen in Fig. 17
[119]. The activation energies obtained in most studies are smaller than $200 \mathrm{meV}$ and only a few deep defects have been observed. In our opinion, these results on the defects are not enough to explain the ultra-short minority lifetime of the CZTSSe materials. The undiscovered information may be the key for understanding the efficiency loss mechanism of the cell.

\section{Experimental control of defects}

So far, many efforts have been made to suppress the detrimental defects in CZTSSe. Intrinsic doping (i.e., composition regulation of $\mathrm{Cu}, \mathrm{Zn}$, and $\mathrm{Sn}$ ), cationic substitution with iso-electronic elements (i.e., the elements from the same family as $\mathrm{Cu}, \mathrm{Zn}$, and $\mathrm{Sn}$ ), and extrinsic doping with alkaline elements are the most investigated ones. Meanwhile, less conventional options such as $\mathrm{Ba}, \mathrm{Mn}, \mathrm{Fe}, \mathrm{Co}$, and $\mathrm{Ni}$ have also been reported for alloying [120-123].

From the early-stage development of kesterite materials, it has been known that an off-stoichiometric composition is required to obtain high-efficiency devices $[23,124-126]$. Generally, the grains of absorber grow
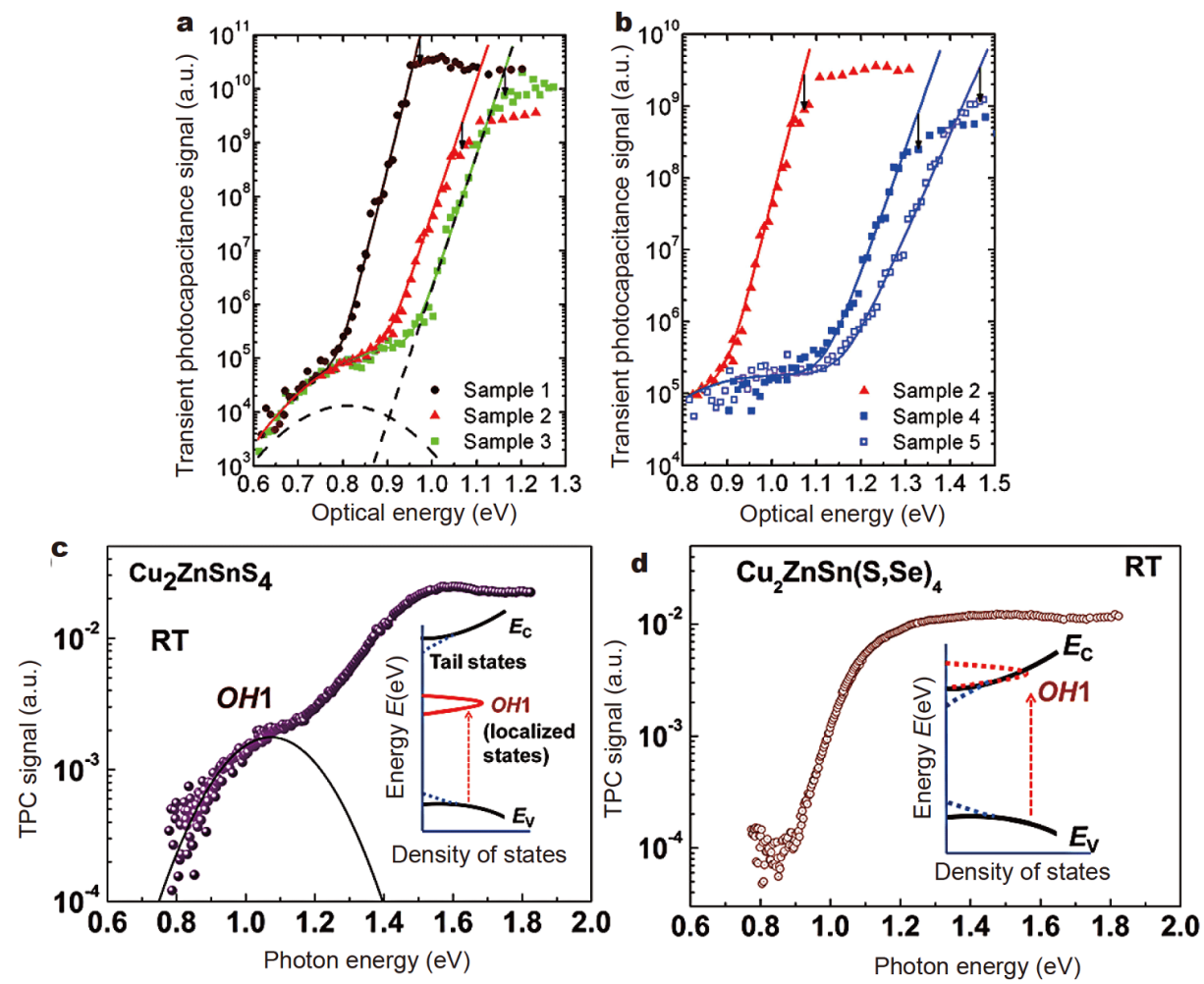

Figure 16 (a, b) TPC spectra for five CZTSSe samples obtained by Miller et al. The bandgaps of samples 1 to 5 are 1.07, 1.15, 1.20, 1.47 and 1.51, respectively. Reprinted with permission from Ref. [89]. Copyright 2012, AIP publishing. TPC spectra of (c) CZTS and (d) CZTSSe (S/(S+Se)=0.15) solar cells measured by Islam et al. Solid black line is the Gaussian fitting of the defect band, OH1. Insets of figures show schematic diagram of the sub-band-gap optical transitions in the films. Reprinted with permission from Ref. [90]. Copyright 2015, AIP publishing. 


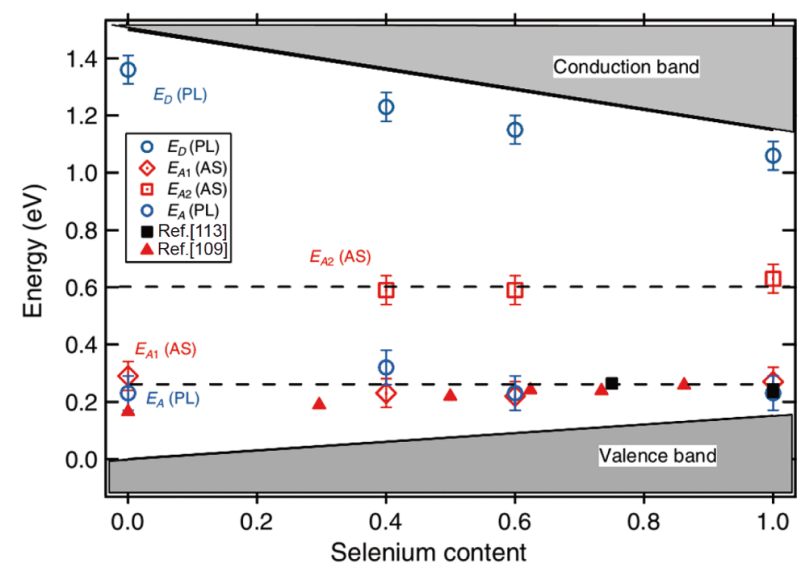

Figure 17 A schematic defect band diagram of the defect levels for CZTSSe devices. Dashed lines are guides to the eye. Reprinted with permission from Ref. [119]. Copyright 2016, APS publishing.

under $\mathrm{Cu}$-poor and $\mathrm{Zn}$-rich conditions, which can help to suppress the formation of secondary phases, such as $\mathrm{Cu}$ $\mathrm{X}, \mathrm{Sn}-\mathrm{X}$, and $\mathrm{Cu}-\mathrm{Sn}-\mathrm{X}\left(\mathrm{X}=\mathrm{S}\right.$ or Se). Meanwhile, $\mathrm{V}_{\mathrm{Cu}}$ tends to form in CZTSSe under such conditions, helping increase the conductivity. The $\mathrm{Sn}$ content has also exhibited an important effect on the defect properties of CZTSSe thin films. Larramona et al. [101] eliminated the deep defect $\left(\mathrm{V}_{\mathrm{Sn}}\right.$ or $\left.\mathrm{Cn}_{\mathrm{Sn}}\right)$ centered at $E_{v}+600 \mathrm{meV}$ by finetuning the Sn content, and achieved $10.8 \%$ solar cell efficiency from a spray-deposition method. Haass et al. [52] proposed that there is complex interplay between the doped alkali elements and absorber composition, especially the Sn content. The most efficient solar cells doped with different alkali metals correspond to different optimized Sn compositions, and a champion device with $12.3 \%$ efficiency has been achieved. In the view that Snrelated defects are all deep defects, the influence mechanism of Sn component on CZTSSe needs to be further studied and controlled.

The complexity of kesterite means that, even in the most favorable cases, there are intrinsic harmful defects due to composition or processing issues. The extrinsic doping with iso-electronic elements has been introduced to compensate such defects. Research on $\mathrm{Ag}$ replacing $\mathrm{Cu}$ has received widespread attention in this regard [106,127-129]. The formation energy of $\mathrm{Ag}_{\mathrm{Zn}}$ in $\mathrm{Ag}_{2} \mathrm{ZnSnS}_{4}$ (AZTS) is larger than that of $\mathrm{Cu}_{\mathrm{Zn}}$ in CZTS, as well as the formation energies of related defect clusters, such as $\left[\mathrm{Ag}_{\mathrm{Zn}}+\mathrm{Zn}_{\mathrm{Ag}}\right]$ and $\left[2 \mathrm{Ag}_{\mathrm{Sn}}+\mathrm{Sn}_{\mathrm{Zn}}\right]$ in AZTS [130]. Besides, the energy level of Ag- and $\mathrm{Zn}$-related defects in AZTS is lower than that in CZTS. Therefore, $\mathrm{Cu}$ substitution by Ag in CZTSSe has been expected to suppress the $\mathrm{Cu} / \mathrm{Zn}$ disorder and associated band tail states. Qi et al. [51] reported that $\mathrm{Ag}_{\mathrm{Cu}}$ substitution can decrease both the density and the energy level of $\mathrm{Cu}_{\mathrm{Zn}}$ and $\mathrm{Cu}_{\mathrm{Sn}}$ defects (Fig. 18a and b), and achieved an 11.2\% efficiency for Aggraded device. Cd doping was also applied in CZTSSe [131-134]. Although the theoretical calculation showed that replacing $\mathrm{Zn}$ with $\mathrm{Cd}$ cannot significantly reduce the formation energy of antisite defects or defect clusters [130], some studies have still exhibited that Cd-alloying has positive influence on the CZTSSe. Yan et al. [59] found that the $E_{\mathrm{U}}$ of Cd-alloying CZTS became smaller (Fig. 18c) and up to $11.5 \%$ efficiency solar cell was obtained. Sun et al. [58] showed that the activation energy of dominant defect turned from $118 \mathrm{meV}$ in CZTSSe to $38 \mathrm{meV}$ in Cd-alloying CZTSSe (Fig. 18d). Besides eliminating $\mathrm{Cu} / \mathrm{Zn}$ disorder, approaches of replacing $\mathrm{Sn}$ with Ge were also developed to reduce the probability of formation of Sn-reduced species like $\mathrm{Sn}^{2+}$ that are commonly associated with deep defects. Kim et al. [61] prepared Ge-alloying CZTSe solar cell by co-evaporating $\mathrm{Cu}$, $\mathrm{Zn}, \mathrm{Sn}, \mathrm{Ge}$, and Se, which resulted in an improved minority lifetime and an efficiency of $12.3 \%$. Neuschitzer et al. [135] analyzed Ge-alloying CZTSe samples, and found that appropriate $\mathrm{Sn}$ content can eliminate deep defects such as the $\mathrm{Cu}_{\mathrm{Sn}}$ or $\mathrm{V}_{\mathrm{Sn}}\left(E_{\mathrm{a}}=428 \mathrm{meV}\right)$, while excess $\mathrm{Sn}$ content can lead to the formation of other deep defects such as $\mathrm{Sn}_{\mathrm{Cu}}$ and $\mathrm{Ge}_{\mathrm{Cu}}\left(E_{\mathrm{a}}=438 \mathrm{meV}\right)$ that deteriorate the cell performance, as shown in Fig. 19. Despite these positive and valuable efforts, the efficiencies of the kesterite devices that incorporated element alloying have not yet broken through the maximum record of $12.6 \%$.

Apart from the substitution of cations, alkaline element doping that is inherited from the CIGS field has also shown a strong positive impact on CZTSSe [136]. It was found that Na-doping can increase the carrier concentration of CZTSSe [137-139]. There are two compatible explanations for this phenomenon. The first is that the introduced $\mathrm{Na}$ atoms naturally occupy the $\mathrm{Cu}$ positions, replacing $\mathrm{Zn}$ in $\mathrm{Zn}_{\mathrm{Cu}}$ antisite defects, thus decreasing the concentration of shallow donor and increasing the p-type conductivity [140]. Another possible explanation has considered the change in the alloying solubility of $\mathrm{Na}$ with temperature. Under the high temperature condition of the CZTSSe synthesis $\left(>500^{\circ} \mathrm{C}\right), \mathrm{Na}$ is highly soluble in kesterite, occupying the $\mathrm{Cu}$ position. During the cooling process, Na solubility strongly decreases, separating out toward the grain boundaries and leaving $\mathrm{V}_{\mathrm{Cu}}$ in the grains [141]. Besides $\mathrm{Na}$, K-doping exhibited the similar result. Studies on the doping of the smallest-sized alkali metal $\mathrm{Li}$ indicated that the properties 

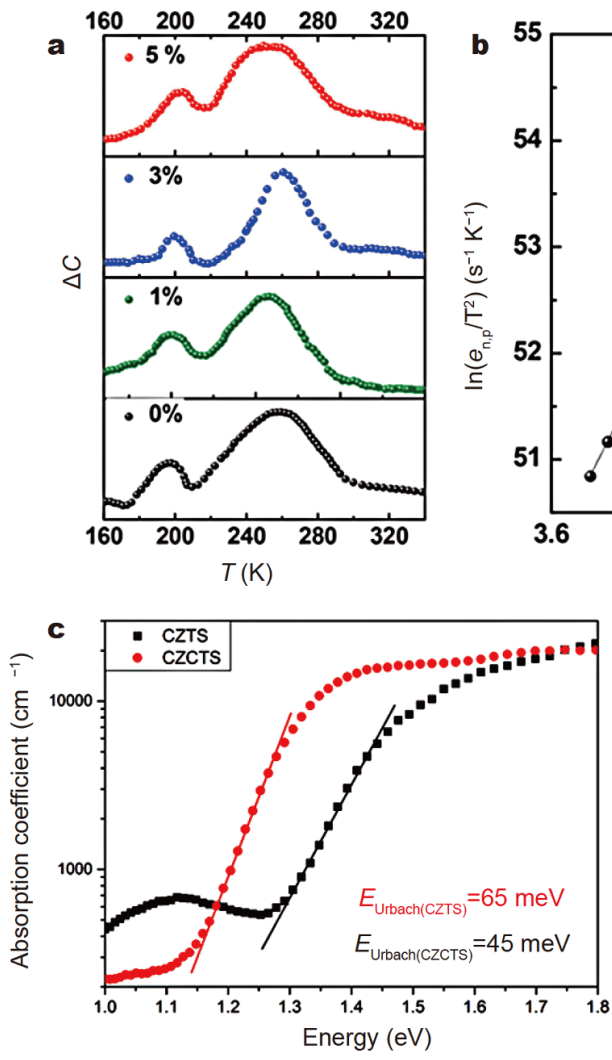
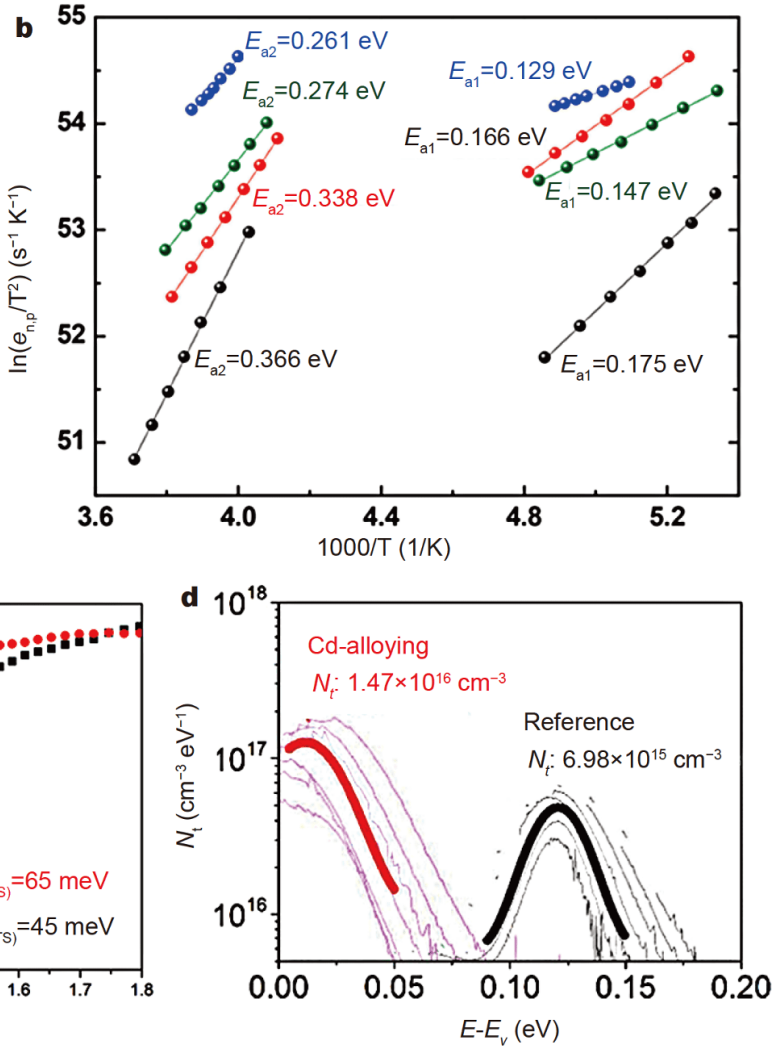

Figure 18 (a) C-DLTS signals of $(\mathrm{Cu}, \mathrm{Ag})_{2} \mathrm{ZnSn}(\mathrm{S}, \mathrm{Se})_{4}$ solar cells with different ratios of $\mathrm{Ag} /(\mathrm{Ag}+\mathrm{Cu})$. (b) Arrhenius plots corresponding to the peaks derived from C-DLTS spectra. Reprinted with permission from Ref. [106]. Copyright 2017, ACS publishing. (c) Absorption coefficients for CZTS and Cd-alloying CZTS (CZCTS) obtained from photothermal deflection spectroscopy. The inverse of the slope from the linear part below the band gap energy provides the $E_{\mathrm{U}}$. Reprinted with permission from Ref. [59]. Copyright 2017, ACS publishing. (d) Defect density spectra derived from admittance spectra. Reprinted with permission from Ref. [58]. Copyright 2017, Elsevier.

of grain and grain boundary are affected simultaneously. Yang et al. [142] proposed that $\mathrm{Li}$ atoms can enter into the lattice to form $(\mathrm{Li}, \mathrm{Cu})_{2} \mathrm{ZnSn}(\mathrm{S}, \mathrm{Se})_{4}$ alloy, and thus can adjust the bandgap value of the absorber. Xin et al. [47] observed that the contact potential difference at the grain boundaries turned from positive to negative after Li-doping, which may be caused by the formation of the insulating thin layer such as $\mathrm{LiO}_{2}, \mathrm{LiS}_{2}, \mathrm{LiSe}_{2}$, and $\mathrm{Li}_{2} \mathrm{SnO}_{3}$. In this case, the grain boundaries can act as the hole channel and electron barrier, which is considered to be superior to that where the grain boundaries act as the electron channel. After trying a variety of alkali metals, Haass et al. [52] obtained the highest efficiency of $12.3 \%$ by the Li-doping. The synergy effect of the above three methods, such as alkali metal+Sn [52], and $\mathrm{Na}+\mathrm{Ge}$ $[135,143]$, has also been studied. In our opinion, compared with these doping strategies, improving the fabrication technology of CZTSSe absorption layer is the most direct and effective way to control the defects and enhance the efficiency. A systematic improvement of the preparation process is based on a deep understanding of the crystallization mechanism, which is another topic and we will not talk here.

\section{CONCLUSION AND PERSPECTIVES}

In this review, we present a systematical discussion about the efficiency loss-related atomic disorder and defect properties of the CZTSSe. Ever since the record efficiency of $12.6 \%$ in CZTSSe solar cell was realized by a hydrazinebased method in 2013, the efficiency has been experiencing a bottleneck with a $V_{\mathrm{OC}}$ deficit in the range of $0.57-0.62 \mathrm{~V}$. However, the material and physics mechanism behind this giant voltage loss has not been clearly clarified until now. The large $V_{\mathrm{OC}}$ deficit was once believed to be associated with the prevalence of severe band tailing induced by atomic disorder. To understand 

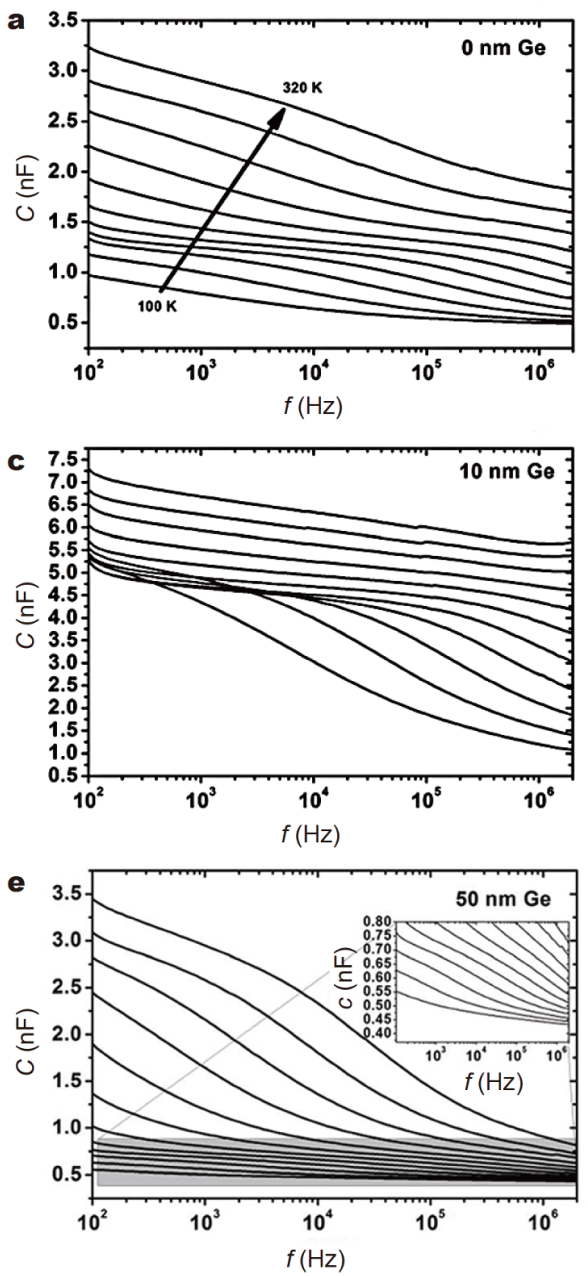
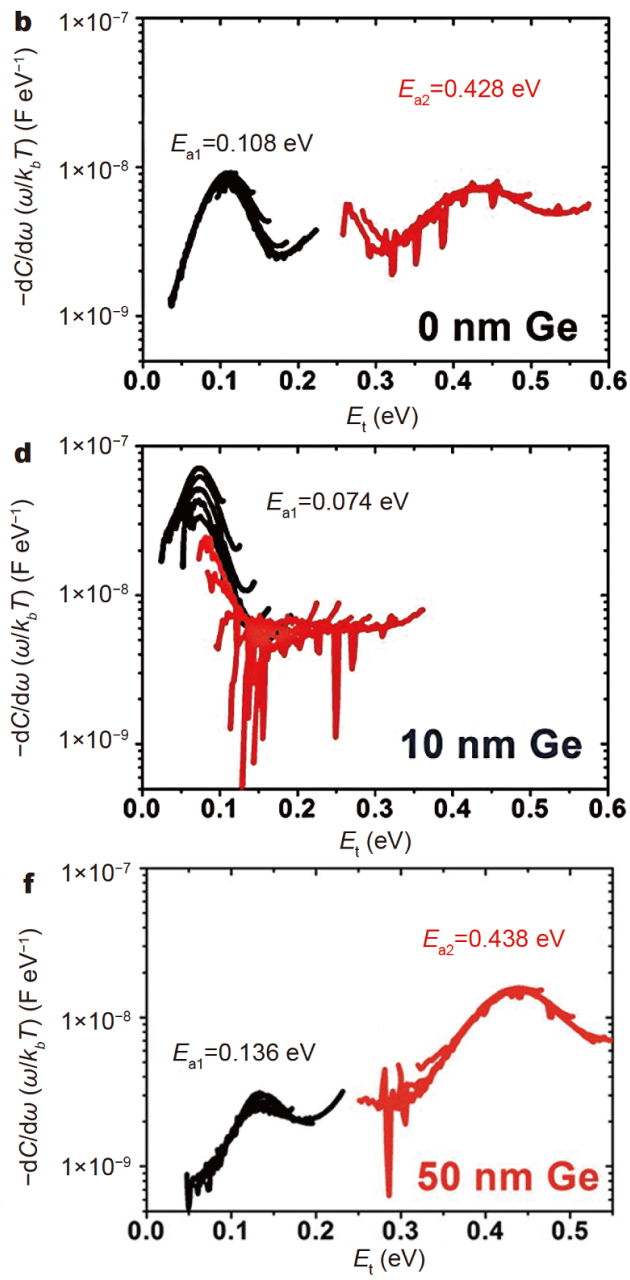

Figure 19 (a, c, e) Temperature-dependent admittance spectra and (b, d, f) defect spectra derived from them for CZTSe solar cells with different Ge doping quantities. Reprinted with permission from Ref. [135]. Copyright 2018, RSC publishing.

and resolve this issue, researchers have steered their study interest towards the $\mathrm{Cu} / \mathrm{Zn}$ disorder, adjusting the disordering by long annealing, tracking the order level change by Raman spectra, and quantifying the bandgap fluctuations amplitude caused by $\mathrm{Cu} / \mathrm{Zn}$ disorder. Recently, the research of deep defects in CZTSSe, especially the effective non-radiative recombination centers, has been on the rise. Theoretical calculations have shown that the lone-pair $\left(5 \mathrm{~s}^{2}\right)$ effect associated with $\mathrm{Sn}$ is responsible for both the deep defect levels and lager lattice distortions that facilitate the electron-hole non-radiative recombination. Nevertheless, this explanation still lacks direct experimental proof. Based on the findings about disorder and deep defects, we suggest that a synergy effect may exist between different defects in causing the charge recombination, that is, deep defects act as the killer de- fects while $\mathrm{Cu}_{\mathrm{Zn}}$ and $\mathrm{Zn}_{\mathrm{Cu}}$ antisites assist fast charge capturing. Furthermore, the defect identification in the CZTSSe system has been summarized and discussed in this review. Although several shallow defects $\left(\mathrm{V}_{\mathrm{Cu}}, \mathrm{Cu}_{\mathrm{Zn}}\right.$, $\left.\mathrm{Zn}_{\mathrm{Sn}_{\mathrm{n}}}\right)$ and few deep defects $\left(\mathrm{Cu}_{\mathrm{Sn}_{\mathrm{n}}}, \mathrm{V}_{\mathrm{Sn}_{\mathrm{n}}}\right)$ have been detected in the CZTSSe samples, the obtained defect information are still not enough to explain the extremely short carrier lifetime in kesterite. Many efforts have been made to suppress the detrimental defects in CZTSSe, doping isoelectronic/alkaline elements. Nonetheless, the record of the CZTSSe device is still waiting to break through.

Although numerous published studies have explored the defect properties of CZTSSe, there are still some important issues unresolved. The hidden mechanisms limiting the minority lifetime of the CZTSSe materials and the device voltage need to be further investigated. 


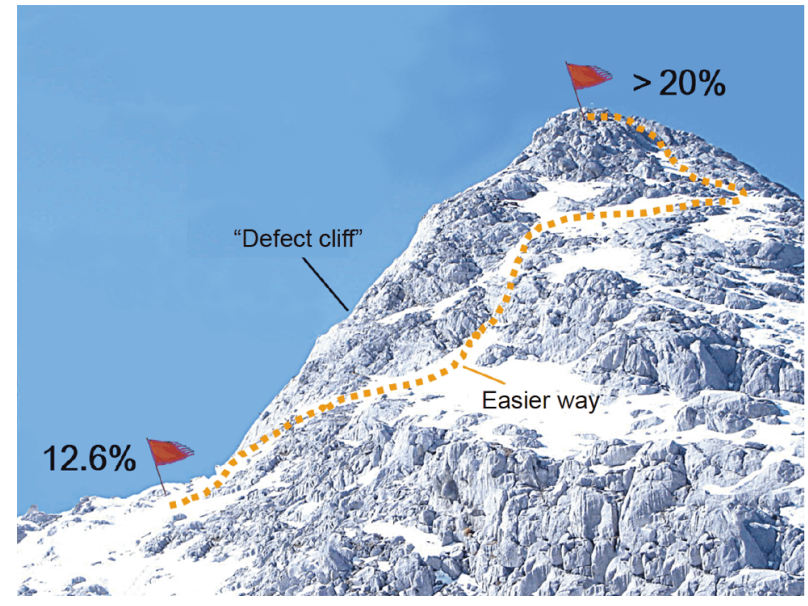

Figure 20 Schematic diagram of the two ways to the "high efficiency" destination. The mountain background is a photo taken by a Chinese netizen [144].

The properties of different defects and their effects on the device performance have not been fully clarified yet. It is still a challenge to accurately evaluate the $\mathrm{Cu} / \mathrm{Zn}$ disorder in film samples and the carrier capture cross-section of defects from experimental measurements to theoretical calculations. More new and independent methods are desired to be developed and exploited to probe the defect properties of the CZTSSe and to investigate the defectrelated charge recombination processes. It is necessary to explore new experimental characterization methods and regulation methods, combining with complicated theoretical calculations and the establishment of mechanism models to deal with these problems, which is indeed a huge challenge, just like climbing a steep cliff, requiring the cooperation and efforts of numerous researchers. Nonetheless, there may be another way waiting to be discovered (Fig. 20 [144]), which can bypass this obstacle and then make it easier to reach our destination. We sincerely hope more and more research interest and resources can be focused on the study of CZTSSe solar cell. Overcoming the defect and efficiency limit of the CZTSSe device is not just an issue for the thin-film photovoltaic field, but more importantly has giant implications for the compound semiconductor science and technology.

Received 13 April 2020; accepted 6 May 2020;

published online 6 August 2020

1 Burger B, Kiefer K, Kost C, et al. Photovoltaics Report. Freiburg: Fraunhofer ISE, 2019

2 Xiong S, Zhu M. Fundamentals and Applications of Solar Cells. 1st ed. Beijing: Science Press, 2007

3 Luque A, Hegedus S. Handbook of Photovoltaic Science and Engineering. 2nd ed. Chichester: Wiley, 2011
4 Polman A, Knight M, Garnett EC, et al. Photovoltaic materials: Present efficiencies and future challenges. Science, 2016, 352: aad 4424

5 NREL. Best Research-Cell Efficiencies. https://www.nrel.gov/pv/ assets/pdfs/pv-efficiency-chart.pdf (accessed 6 November, 2019)

6 Fthenakis V, Wang W, Kim HC. Life cycle inventory analysis of the production of metals used in photovoltaics. Renew Sustain Energy Rev, 2009, 13: 493-517

7 Chen S, Yang JH, Gong XG, et al. Intrinsic point defects and complexes in the quaternary kesterite semiconductor $\mathrm{Cu}_{2} \mathrm{ZnSnS}_{4}$. Phys Rev B, 2010, 81: 245204

8 Scragg JJ, Dale PJ, Peter LM, et al. New routes to sustainable photovoltaics: Evaluation of $\mathrm{Cu}_{2} \mathrm{ZnSnS}_{4}$ as an alternative absorber material. Phys Stat Sol B, 2008, 245: 1772-1778

9 Kamoun N, Bouzouita H, Rezig B. Fabrication and characterization of $\mathrm{Cu}_{2} \mathrm{ZnSnS}_{4}$ thin films deposited by spray pyrolysis technique. Thin Solid Films, 2007, 515: 5949-5952

10 Park D, Nam D, Jung S, et al. Optical characterization of $\mathrm{Cu}_{2} \mathrm{ZnSnSe}_{4}$ grown by thermal co-evaporation. Thin Solid Films, 2011, 519: 7386-7389

11 Zhang $\mathrm{X}$, Han $\mathrm{Y}$, Chai SZ, et al. Advances in $\mathrm{Cu}_{2} \mathrm{ZnSn}(\mathrm{S}, \mathrm{Se})_{4}$ thin film solar cells. Acta Physico-Chim Sin, 2016, 32: 1330-1346

12 Katagiri H, Saitoh K, Washio T, et al. Development of thin film solar cell based on $\mathrm{Cu}_{2} \mathrm{ZnSnS}_{4}$ thin films. Sol Energy Mater Sol Cells, 2001, 65: 141-148

13 Wang W, Winkler MT, Gunawan O, et al. Device characteristics of CZTSSe thin-film solar cells with $12.6 \%$ efficiency. Adv Energy Mater, 2014, 4: 1301465

14 Fan $\mathrm{Y}$, Qin $\mathrm{H}, \mathrm{Mi} \mathrm{B}$, et al. Progress in the fabrication of $\mathrm{Cu}_{2} \mathrm{ZnSnS}_{4}$ thin film for solar cells. Acta Chim Sin, 2014, 72: 643-652

15 Siebentritt S. Why are kesterite solar cells not $20 \%$ efficient? Thin Solid Films, 2013, 535: 1-4

16 Mitzi DB, Gunawan O, Todorov TK, et al. The path towards a high-performance solution-processed kesterite solar cell. Sol Energy Mater Sol Cells, 2011, 95: 1421-1436

17 Yang KJ, Sim JH, Son DH, et al. Effects of the compositional ratio distribution with sulfurization temperatures in the absorber layer on the defect and surface electrical characteristics of $\mathrm{Cu}_{2} \mathrm{ZnSnS}_{4}$ solar cells. Prog Photovolt-Res Appl, 2015, 23: 1771-1784

18 Zhou H, Hsu WC, Duan HS, et al. CZTS nanocrystals: A promising approach for next generation thin film photovoltaics. Energy Environ Sci, 2013, 6: 2822-2838

19 Azimi H, Hou Y, Brabec CJ. Towards low-cost, environmentally friendly printed chalcopyrite and kesterite solar cells. Energy Environ Sci, 2014, 7: 1829-1849

20 Wang D, Zhao W, Zhang Y, et al. Path towards high-efficient kesterite solar cells. J Energy Chem, 2018, 27: 1040-1053

21 Kim J, Shin B. Strategies to reduce the open-circuit voltage deficit in $\mathrm{Cu}_{2} \mathrm{ZnSn}(\mathrm{S}, \mathrm{Se})_{4}$ thin film solar cells. Electron Mater Lett, 2017, 13: $373-392$

22 Gao S, Jiang Z, Wu L, et al. Interfaces of high-efficiency kesterite $\mathrm{Cu}_{2} \mathrm{ZnSnS}(\mathrm{e})_{4}$ thin film solar cells. Chin Phys B, 2018, 27: 018803

23 Walsh A, Chen S, Wei SH, et al. Kesterite thin-film solar cells: Advances in materials modelling of $\mathrm{Cu}_{2} \mathrm{ZnSnS}_{4}$. Adv Energy Mater, 2012, 2: 400-409

24 Chen S, Walsh A, Yang JH, et al. Compositional dependence of structural and electronic properties of $\mathrm{Cu}_{2} \mathrm{ZnSn}(\mathrm{S}, \mathrm{Se})_{4}$ alloys for thin film solar cells. Phys Rev B, 2011, 83: 125201

25 Sun K, Huang J, Yan C, et al. Self-assembled nanometer-scale ZnS 
structure at the CZTS/ZnCdS heterointerface for high-efficiency wide band gap $\mathrm{Cu}_{2} \mathrm{ZnSnS}_{4}$ solar cells. Chem Mater, 2018, 30: 4008-4016

26 Gour KS, Parmar R, Kumar R, et al. Cd-free $\mathrm{Zn}(\mathrm{O}, \mathrm{S})$ as alternative buffer layer for chalcogenide and kesterite based thin films solar cells: A review. J Nanosci Nanotechnol, 2020, 20: 3622-3635

$27 \mathrm{Yu} \mathrm{J}$, Zheng Z, Dong L, et al. Effect of deposited temperatures of the buffer layer on the band offset of CZTS/ $\mathrm{In}_{2} \mathrm{~S}_{3}$ heterostructure and its solar cell performance. Chin Phys B, 2017, 26: 046802

28 Kim J, Hiroi $\mathrm{H}$, Todorov TK, et al. High efficiency $\mathrm{Cu}_{2} \mathrm{ZnSn}(\mathrm{S}, \mathrm{Se})_{4}$ solar cells by applying a double $\mathrm{In}_{2} \mathrm{~S}_{3} / \mathrm{CdS}$ emitter. Adv Mater, 2014, 26: 7427-7431

29 Scragg JJ, Wätjen JT, Edoff M, et al. A detrimental reaction at the molybdenum back contact in $\mathrm{Cu}_{2} \mathrm{ZnSn}(\mathrm{S}, \mathrm{Se})_{4}$ thin-film solar cells. J Am Chem Soc, 2012, 134: 19330-19333

30 Shin B, Bojarczuk NA, Guha S. On the kinetics of $\mathrm{MoSe}_{2}$ interfacial layer formation in chalcogen-based thin film solar cells with a molybdenum back contact. Appl Phys Lett, 2013, 102: 091907

31 Yang KJ, Sim JH, Jeon B, et al. Effects of $\mathrm{Na}$ and $\mathrm{MoS}_{2}$ on $\mathrm{Cu}_{2} \mathrm{ZnSnS}_{4}$ thin-film solar cell. Prog Photovolt-Res Appl, 2015, 23: $862-873$

32 Gao S, Zhang Y, Ao J, et al. Tailoring $\mathrm{Mo}(\mathrm{S}, \mathrm{Se})_{2}$ structure for high efficient $\mathrm{Cu}_{2} \mathrm{ZnSn}(\mathrm{S}, \mathrm{Se})_{4}$ solar cells. Sol Energy Mater Sol Cells, 2018, 176: 302-309

33 Li J, Zhang Y, Zhao W, et al. A temporary barrier effect of the alloy layer during selenization: Tailoring the thickness of $\mathrm{MoSe}_{2}$ for efficient $\mathrm{Cu}_{2} \mathrm{ZnSnSe}_{4}$ solar cells. Adv Energy Mater, 2015, 5: 1402178

34 Min X, Guo L, Yu Q, et al. Enhancing back interfacial contact by in-situ prepared $\mathrm{MoO}_{3}$ thin layer for $\mathrm{Cu}_{2} \mathrm{ZnSnS}_{x} \mathrm{Se}_{4-x}$ solar cells. Sci China Mater, 2019, 62: 797-802

35 Sun $\mathrm{K}$, Yan C, Liu F, et al. Over $9 \%$ efficient kesterite $\mathrm{Cu}_{2} \mathrm{ZnSnS}_{4}$ solar cell fabricated by using $\mathrm{Zn}_{1-x} \mathrm{Cd}_{x} \mathrm{~S}$ buffer layer. Adv Energy Mater, 2016, 6: 1600046

36 Park J, Huang J, Yun J, et al. The role of hydrogen from ALD$\mathrm{Al}_{2} \mathrm{O}_{3}$ in kesterite $\mathrm{Cu}_{2} \mathrm{ZnSnS}_{4}$ solar cells: Grain surface passivation. Adv Energy Mater, 2018, 8: 1701940

37 Chen S, Walsh A, Gong XG, et al. Classification of lattice defects in the kesterite $\mathrm{Cu}_{2} \mathrm{ZnSnS}_{4}$ and $\mathrm{Cu}_{2} \mathrm{ZnSnSe}_{4}$ earth-abundant solar cell absorbers. Adv Mater, 2013, 25: 1522-1539

38 Gokmen T, Gunawan O, Todorov TK, et al. Band tailing and efficiency limitation in kesterite solar cells. Appl Phys Lett, 2013, 103: 103506

39 Kumar MS, Madhusudanan SP, Batabyal SK. Substitution of Zn in earth-abundant $\mathrm{Cu}_{2} \mathrm{ZnSn}(\mathrm{S}, \mathrm{Se})_{4}$ based thin film solar cells-A status review. Sol Energy Mater Sol Cells, 2018, 185: 287-299

40 Moore JE, Hages CJ, Agrawal R, et al. The importance of band tail recombination on current collection and open-circuit voltage in CZTSSe solar cells. Appl Phys Lett, 2016, 109: 021102

41 Bourdais S, Choné C, Delatouche B, et al. Is the $\mathrm{Cu} / \mathrm{Zn}$ disorder the main culprit for the voltage deficit in kesterite solar cells? Adv Energy Mater, 2016, 6: 1502276

$42 \mathrm{Li}$ J, Yuan ZK, Chen S, et al. Effective and noneffective recombination center defects in $\mathrm{Cu}_{2} \mathrm{ZnSnS}_{4}$ : Significant difference in carrier capture cross sections. Chem Mater, 2018, 31: 826-833

43 Kim S, Park JS, Walsh A. Identification of killer defects in kesterite thin-film solar cells. ACS Energy Lett, 2018, 3: 496-500

44 Katagiri $\mathrm{H} . \mathrm{Cu}_{2} \mathrm{ZnSnS}_{4}$ thin film solar cells. Thin Solid Films, 2005, 480-481: 426-432

45 Jimbo K, Kimura R, Kamimura T, et al. $\mathrm{Cu}_{2} \mathrm{ZnSnS}_{4}$-type thin film solar cells using abundant materials. Thin Solid Films, 2007, 515: 5997-5999

46 Katagiri H, Jimbo K, Yamada S, et al. Enhanced conversion efficiencies of $\mathrm{Cu}_{2} \mathrm{ZnSnS}_{4}$-based thin film solar cells by using preferential etching technique. Appl Phys Express, 2008, 1: 041201

47 Xin H, Vorpahl SM, Collord AD, et al. Lithium-doping inverts the nanoscale electric field at the grain boundaries in $\mathrm{Cu}_{2} \mathrm{ZnSn}(\mathrm{S}, \mathrm{Se})_{4}$ and increases photovoltaic efficiency. Phys Chem Chem Phys, 2015, 17: 23859-23866

48 Haass SG, Diethelm M, Werner M, et al. $11.2 \%$ efficient solution processed kesterite solar cell with a low voltage deficit. Adv Energy Mater, 2015, 5: 1500712

49 Todorov TK, Tang J, Bag S, et al. Beyond 11\% efficiency: Characteristics of state-of-the-art $\mathrm{Cu}_{2} \mathrm{ZnSn}(\mathrm{S}, \mathrm{Se})_{4}$ solar cells. Adv Energy Mater, 2013, 3: 34-38

50 Duan B, Guo L, Yu Q, et al. Highly efficient solution-processed CZTSSe solar cells based on a convenient sodium-incorporated post-treatment method. J Energy Chem, 2020, 40: 196-203

51 Qi YF, Kou DX, Zhou WH, et al. Engineering of interface band bending and defects elimination via a Ag-graded active layer for efficient $(\mathrm{Cu}, \mathrm{Ag})_{2} \mathrm{ZnSn}(\mathrm{S}, \mathrm{Se})_{4}$ solar cells. Energy Environ Sci, 2017, 10: 2401-2410

52 Haass SG, Andres C, Figi R, et al. Complex interplay between absorber composition and alkali doping in high-efficiency kesterite solar cells. Adv Energy Mater, 2017, 8: 1701760

53 Cabas-Vidani A, Haass SG, Andres C, et al. High-efficiency $\left(\mathrm{Li}_{x} \mathrm{Cu}_{1-x}\right)_{2} \mathrm{ZnSn}(\mathrm{S}, \mathrm{Se})_{4}$ kesterite solar cells with lithium alloying. Adv Energy Mater, 2018, 8: 1801191

54 Lee YS, Gershon T, Gunawan O, et al. $\mathrm{Cu}_{2} \mathrm{ZnSnSe}_{4}$ thin-film solar cells by thermal co-evaporation with $11.6 \%$ efficiency and improved minority carrier diffusion length. Adv Energy Mater, 2015, 5: 1401372

55 Kim SY, Son DH, Kim YI, et al. Void and secondary phase formation mechanisms of CZTSSe using $\mathrm{Sn} / \mathrm{Cu} / \mathrm{Zn} / \mathrm{Mo}$ stacked elemental precursors. Nano Energy, 2019, 59: 399-411

56 Yang KJ, Son DH, Sung SJ, et al. A band-gap-graded CZTSSe solar cell with 12.3\% efficiency. J Mater Chem A, 2016, 4: 1015110158

57 Yan C, Huang J, Sun K, et al. $\mathrm{Cu}_{2} \mathrm{ZnSnS}_{4}$ solar cells with over $10 \%$ power conversion efficiency enabled by heterojunction heat treatment. Nat Energy, 2018, 3: 764-772

58 Sun $\mathrm{R}$, Zhuang $\mathrm{D}$, Zhao $\mathrm{M}$, et al. Beyond $11 \%$ efficient $\mathrm{Cu}_{2} \mathrm{ZnSn}(\mathrm{Se}, \mathrm{S})_{4}$ thin film solar cells by cadmium alloying. Sol Energy Mater Sol Cells, 2018, 174: 494-498

59 Yan C, Sun K, Huang J, et al. Beyond $11 \%$ efficient sulfide kesterite $\mathrm{Cu}_{2} \mathrm{Zn}_{x} \mathrm{Cd}_{1-x} \mathrm{SnS}_{4}$ solar cell: Effects of cadmium alloying. ACS Energy Lett, 2017, 2: 930-936

60 Son DH, Kim SH, Kim SY, et al. Effect of solid- $\mathrm{H}_{2} \mathrm{~S}$ gas reactions on CZTSSe thin film growth and photovoltaic properties of a 12.62\% efficiency device. J Mater Chem A, 2019, 7: 25279-25289

61 Kim S, Kim KM, Tampo H, et al. Improvement of voltage deficit of Ge-incorporated kesterite solar cell with $12.3 \%$ conversion efficiency. Appl Phys Express, 2016, 9: 102301

62 Giraldo S, Saucedo E, Neuschitzer M, et al. How small amounts of Ge modify the formation pathways and crystallization of kesterites. Energy Environ Sci, 2018, 11: 582-593

63 Green MA, Dunlop ED, Levi DH, et al. Solar cell efficiency tables (version 54). Prog Photovolt Res Appl, 2019, 27: 565-575

64 Kim SY, Rana TR, Kim JH, et al. Limiting effects of conduction band offset and defect states on high efficiency CZTSSe solar cell. 
Nano Energy, 2018, 45: 75-83

65 Shockley W, Queisser HJ. Detailed balance limit of efficiency of $p$ $n$ junction solar cells. J Appl Phys, 1961, 32: 510-519

66 Sze SM, Ng KK. Physics of Semiconductor Devices. 3rd ed. Hoboken: Wiley, 2006

67 Tai KF, Gershon T, Gunawan O, et al. Examination of electronic structure differences between CIGSSe and CZTSSe by photoluminescence study. J Appl Phys, 2015, 117: 235701

68 Romero MJ, Du H, Teeter G, et al. Comparative study of the luminescence and intrinsic point defects in the kesterite $\mathrm{Cu}_{2} \mathrm{ZnSnS}_{4}$ and chalcopyrite $\mathrm{Cu}(\mathrm{In}, \mathrm{Ga}) \mathrm{Se}_{2}$ thin films used in photovoltaic applications. Phys Rev B, 2011, 84: 165324

69 Shin D, Saparov B, Mitzi DB. Defect engineering in multinary earth-abundant chalcogenide photovoltaic materials. Adv Energy Mater, 2017, 7: 1602366

70 Gershon T, Shin B, Bojarczuk N, et al. Photoluminescence characterization of a high-efficiency $\mathrm{Cu}_{2} \mathrm{ZnSnS}_{4}$ device. J Appl Phys, 2013, 114: 154905

71 Shklovskii BI, Efros AL. Electronic Properties of Doped Semiconductors. 1st ed. Berlin: Springer, 1984

72 Dirnstorfer I, Wagner M, Hofmann DM, et al. Characterization of CuIn $(\mathrm{Ga}) \mathrm{Se}_{2}$ Thin Films. Phys Stat Solidi A, 1998, 168: 163175

73 Mattheis J, Rau U, Werner JH. Light absorption and emission in semiconductors with band gap fluctuations-A study on $\mathrm{Cu}(\mathrm{In}, \mathrm{Ga}) \mathrm{Se}_{2}$ thin films. J Appl Phys, 2007, 101: 113519

74 Khare A, Himmetoglu B, Johnson M, et al. Calculation of the lattice dynamics and Raman spectra of copper zinc tin chalcogenides and comparison to experiments. J Appl Phys, 2012, 111: 083707

75 Chen S, Gong XG, Walsh A, et al. Crystal and electronic band structure of $\mathrm{Cu}_{2} \mathrm{ZnSnX}_{4}(\mathrm{X}=\mathrm{S}$ and $\mathrm{Se}$ ) photovoltaic absorbers: First-principles insights. Appl Phys Lett, 2009, 94: 041903

76 Schorr S. The crystal structure of kesterite type compounds: A neutron and X-ray diffraction study. Sol Energy Mater Sol Cells, 2011, 95: 1482-1488

77 Choubrac L, Paris M, Lafond A, et al. Multinuclear $\left({ }^{67} \mathrm{Zn},{ }^{119} \mathrm{Sn}\right.$ and ${ }^{65} \mathrm{Cu}$ ) NMR spectroscopy-an ideal technique to probe the cationic ordering in $\mathrm{Cu}_{2} \mathrm{ZnSnS}_{4}$ photovoltaic materials. Phys Chem Chem Phys, 2013, 15: 10722-10725

78 Schorr S, Hoebler HJ, Tovar M. A neutron diffraction study of the stannite-kesterite solid solution series. ejm, 2007, 19: 65-73

79 Bragg WL, Williams EJ. The effect of thermal agitation on atomic arrangement in alloys. Proc R Soc Lond A, 1934, 145: 699-730

80 Vineyard GH. Theory of order-disorder kinetics. Phys Rev, 1956, 102: 981-992

81 Scragg JJS, Choubrac L, Lafond A, et al. A low-temperature orderdisorder transition in $\mathrm{Cu}_{2} \mathrm{ZnSnS}_{4}$ thin films. Appl Phys Lett, 2014, 104: 041911

82 Valakh MY, Dzhagan VM, Babichuk IS, et al. Optically induced structural transformation in disordered kesterite $\mathrm{Cu}_{2} \mathrm{ZnSnS}_{4}$. JETP Lett, 2013, 98: 255-258

83 Rey G, Redinger A, Sendler J, et al. The band gap of $\mathrm{Cu}_{2} \mathrm{ZnSnSe}_{4}$ : Effect of order-disorder. Appl Phys Lett, 2014, 105: 112106

84 Huang D, Persson C. Band gap change induced by defect complexes in $\mathrm{Cu}_{2} \mathrm{ZnSnS}_{4}$. Thin Solid Films, 2013, 535: 265-269

85 Scragg JJS, Larsen JK, Kumar M, et al. Cu-Zn disorder and band gap fluctuations in $\mathrm{Cu}_{2} \mathrm{ZnSn}(\mathrm{S}, \mathrm{Se})_{4}$ : Theoretical and experimental investigations. Phys Status Solidi B, 2016, 253: 247-254 lateral band-gap fluctuations. Appl Phys Lett, 2004, 84: 37353737

87 Roelofs KE, Guo Q, Subramoney S, et al. Investigation of local compositional uniformity in $\mathrm{Cu}_{2} \mathrm{ZnSn}(\mathrm{S}, \mathrm{Se})_{4}$ thin film solar cells prepared from nanoparticle inks. J Mater Chem A, 2014, 2: 13464-13470

88 De Wolf S, Holovsky J, Moon SJ, et al. Organometallic halide perovskites: Sharp optical absorption edge and its relation to photovoltaic performance. J Phys Chem Lett, 2014, 5: 1035-1039

89 Miller DW, Warren CW, Gunawan O, et al. Electronically active defects in the $\mathrm{Cu}_{2} \mathrm{ZnSn}(\mathrm{Se}, \mathrm{S})_{4}$ alloys as revealed by transient photocapacitance spectroscopy. Appl Phys Lett, 2012, 101: 142106

90 Islam MM, Halim MA, Sakurai T, et al. Determination of deeplevel defects in $\mathrm{Cu}_{2} \mathrm{ZnSn}(\mathrm{S}, \mathrm{Se})_{4}$ thin-films using photocapacitance method. Appl Phys Lett, 2015, 106: 243905

91 Gokmen T, Gunawan O, Mitzi DB. Minority carrier diffusion length extraction in $\mathrm{Cu}_{2} \mathrm{ZnSn}(\mathrm{Se}, \mathrm{S})_{4}$ solar cells. J Appl Phys, 2013, 114: 114511

92 Gunawan O, Todorov TK, Mitzi DB. Loss mechanisms in hydrazine-processed $\mathrm{Cu}_{2} \mathrm{ZnSn}(\mathrm{Se}, \mathrm{S})_{4}$ solar cells. Appl Phys Lett, 2010, 97: 233506

93 Kumar M, Dubey A, Adhikari N, et al. Strategic review of secondary phases, defects and defect-complexes in kesterite CZTS-Se solar cells. Energy Environ Sci, 2015, 8: 3134-3159

94 Shockley W, Read WT. Statistics of the recombinations of holes and electrons. Phys Rev, 1952, 87: 835-842

95 Hall RN. Electron-hole recombination in germanium. Phys Rev, 1952, 87: 387-387

96 Alkauskas A, Yan Q, Van de Walle CG. First-principles theory of nonradiative carrier capture via multiphonon emission. Phys Rev B, 2014, 90: 075202

97 Li J, Zhu HF, Zhang YY, et al. Large carrier-capture rate of $\mathrm{PbI}$ antisite in $\mathrm{CH}_{3} \mathrm{NH}_{3} \mathrm{PbI}_{3}$ induced by heavy atoms and soft phonon modes. Phys Rev B, 2017, 96: 104103

98 Kubo R, Toyozawa Y. Application of the method of generating function to radiative and non-radiative transitions of a trapped electron in a crystal. Prog Theor Phys, 1955, 13: 160-182

99 Huang K. Lattice relaxation and multiphonon transitions. Contemp Phys, 2006, 22: 599-612

100 Kim S, Park JS, Hood SN, et al. Lone-pair effect on carrier capture in $\mathrm{Cu}_{2} \mathrm{ZnSnS}_{4}$ solar cells. J Mater Chem A, 2019, 7: 2686-2693

101 Larramona G, Levcenko S, Bourdais S, et al. Fine-tuning the Sn content in CZTSSe thin films to achieve $10.8 \%$ solar cell efficiency from spray-deposited water-ethanol-based colloidal inks. Adv Energy Mater, 2015, 5: 1501404

102 Min X, Shi J, Guo L, et al. Regulation of $\mathrm{Zn} / \mathrm{Sn}$ ratio in kesterite absorbers to boost $10 \%$ efficiency of $\mathrm{Cu}_{2} \mathrm{ZnSn}(\mathrm{S}, \mathrm{Se})_{4}$ solar cells. Chin Phys B, 2018, 27: 016402

103 Lang DV. Deep-level transient spectroscopy: A new method to characterize traps in semiconductors. J Appl Phys, 1974, 45: 3023-3032

104 Yang D. Semiconductor Materials Testing and Analysis. 1st ed. Beijing: Science Press, 2014

105 Das S, Chaudhuri SK, Bhattacharya RN, et al. Defect levels in $\mathrm{Cu}_{2} \mathrm{ZnSn}\left(\mathrm{S}_{x} \mathrm{Se}_{1-x}\right)_{4}$ solar cells probed by current-mode deep level transient spectroscopy. Appl Phys Lett, 2014, 104: 192106

106 Qi Y, Tian Q, Meng Y, et al. Elemental precursor solution processed $\left(\mathrm{Cu}_{1-x} \mathrm{Ag}_{x}\right)_{2} \mathrm{ZnSn}(\mathrm{S}, \mathrm{Se})_{4}$ photovoltaic devices with over 10\% efficiency. ACS Appl Mater Interfaces, 2017, 9: 21243-21250 
107 Campbell S, Qu Y, Major JD, et al. Direct evidence of causality between chemical purity and band-edge potential fluctuations in nanoparticle ink-based $\mathrm{Cu}_{2} \mathrm{ZnSn}(\mathrm{S}, \mathrm{Se})_{4}$ solar cells. J Phys D-Appl Phys, 2019, 52: 135102

108 Fernandes PA, Sartori AF, Salomé PMP, et al. Admittance spectroscopy of $\mathrm{Cu}_{2} \mathrm{ZnSnS}_{4}$ based thin film solar cells. Appl Phys Lett, 2012, 100: 233504

109 Gunawan O, Gokmen T, Warren CW, et al. Electronic properties of the $\mathrm{Cu}_{2} \mathrm{ZnSn}(\mathrm{Se}, \mathrm{S})_{4}$ absorber layer in solar cells as revealed by admittance spectroscopy and related methods. Appl Phys Lett, 2012, 100: 253905

110 Duan HS, Yang W, Bob B, et al. The role of sulfur in solutionprocessed $\mathrm{Cu}_{2} \mathrm{ZnSn}(\mathrm{S}, \mathrm{Se})_{4}$ and its effect on defect properties. Adv Funct Mater, 2013, 23: 1466-1471

111 Luckert F, Hamilton DI, Yakushev MV, et al. Optical properties of high quality $\mathrm{Cu}_{2} \mathrm{ZnSnSe}_{4}$ thin films. Appl Phys Lett, 2011, 99: 062104

112 Grossberg M, Krustok J, Raudoja J, et al. The role of structural properties on deep defect states in $\mathrm{Cu}_{2} \mathrm{ZnSnS}_{4}$ studied by photoluminescence spectroscopy. Appl Phys Lett, 2012, 101: 102102

113 Kask E, Grossberg M, Josepson $\mathrm{R}$, et al. Defect studies in $\mathrm{Cu}_{2} \mathrm{ZnSnSe}_{4}$ and $\mathrm{Cu}_{2} \mathrm{ZnSn}\left(\mathrm{Se}_{0.75} \mathrm{~S}_{0.25}\right)_{4}$ by admittance and photoluminescence spectroscopy. Mater Sci Semiconductor Processing, 2013, 16: 992-996

114 Walter T, Herberholz R, Müller C, et al. Determination of defect distributions from admittance measurements and application to $\mathrm{Cu}(\mathrm{In}, \mathrm{Ga}) \mathrm{Se}_{2}$ based heterojunctions. J Appl Phys, 1996, 80: 44114420

115 Enkhbat T, Kim SY, Kim JH. Device characteristics of band gap tailored 10.04\% efficient CZTSSe solar cells sprayed from waterbased solution. ACS Appl Mater Interfaces, 2019, 11: 3673536741

116 Lee J, Giles NC, Rajavel D, et al. Donor-acceptor pair luminescence involving the iodine A center in CdTe. J Appl Phys, 1995, 78: $5669-5674$

117 Krustok J, Collan H, Hjelt K. Does the low-temperature Arrhenius plot of the photoluminescence intensity in CdTe point towards an erroneous activation energy? J Appl Phys, 1997, 81: $1442-1445$

118 Cohen JD, Unold T, Gelatos AV, et al. Deep defect structure and carrier dynamics in amorphous silicon and silicon-germanium alloys determined by transient photocapacitance methods. J NonCrystalline Solids, 1992, 141: 142-154

119 Levcenko S, Just J, Redinger A, et al. Deep defects in $\mathrm{Cu}_{2} \mathrm{ZnSn}(\mathrm{S}, \mathrm{Se})_{4}$ solar cells with varying Se content. Phys Rev Appl, 2016, 5: 024004

120 Chen R, Persson C. Electronic and optical properties of $\mathrm{Cu}_{2} \mathrm{XSnS}_{4}$ $(\mathrm{X}=\mathrm{Be}, \mathrm{Mg}, \mathrm{Ca}, \mathrm{Mn}, \mathrm{Fe}$, and $\mathrm{Ni}$ ) and the impact of native defect pairs. J Appl Phys, 2017, 121: 203104

121 Xiao Z, Meng W, Li JV, et al. Distant-atom mutation for better earth-abundant light absorbers: A case study of $\mathrm{Cu}_{2} \mathrm{BaSnSe}_{4}$. ACS Energy Lett, 2016, 2: 29-35

122 Cui Y, Deng R, Wang G, et al. A general strategy for synthesis of quaternary semiconductor $\mathrm{Cu}_{2} \mathrm{MSnS}_{4}\left(\mathrm{M}=\mathrm{Co}^{2+}, \mathrm{Fe}^{2+}, \mathrm{Ni}^{2+}, \mathrm{Mn}^{2+}\right)$ nanocrystals. J Mater Chem, 2012, 22: 23136

123 Li X, Hou Z, Gao S, et al. Efficient optimization of the performance of $\mathrm{Mn}^{2+}$-doped kesterite solar cell: Machine learning aided synthesis of high efficient $\mathrm{Cu}_{2}(\mathrm{Mn}, \mathrm{Zn}) \mathrm{Sn}(\mathrm{S}, \mathrm{Se})_{4}$ solar cells. Sol RRL, 2018, 2: 1800198

124 Xiao W, Wang JN, Zhao XS, et al. Intrinsic defects and Na doping in $\mathrm{Cu}_{2} \mathrm{ZnSnS}_{4}$ : A density-functional theory study. Sol Energy, 2015, 116: 125-132

125 Altamura G, Vidal J. Impact of minor phases on the performances of CZTSSe thin-film solar cells. Chem Mater, 2016, 28: 3540-3563

126 Katagiri H, Jimbo K, Tahara M, et al. The influence of the composition ratio on CZTS-based thin film solar cells. MRS Proc, 2009, 1165: M04

127 Gershon T, Lee YS, Antunez P, et al. Photovoltaic materials and devices based on the alloyed kesterite absorber $\left(\mathrm{Ag}_{x} \mathrm{Cu}_{1-x}\right)_{2} \mathrm{ZnSnSe}_{4}$. Adv Energy Mater, 2016, 6: 1502468

128 Guchhait A, Su Z, Tay YF, et al. Enhancement of open-circuit voltage of solution-processed $\mathrm{Cu}_{2} \mathrm{ZnSnS}_{4}$ solar cells with $7.2 \%$ efficiency by incorporation of silver. ACS Energy Lett, 2016, 1: $1256-1261$

129 Qi Y, Liu Y, Kou D, et al. Enhancing grain growth for efficient solution-processed $(\mathrm{Cu}, \mathrm{Ag})_{2} \mathrm{ZnSn}(\mathrm{S}, \mathrm{Se})_{4}$ solar cells based on acetate precursor. ACS Appl Mater Interfaces, 2020, 12: 1421314223

130 Yuan ZK, Chen S, Xiang H, et al. Engineering solar cell absorbers by exploring the band alignment and defect disparity: The case of Cu- and Ag-based kesterite compounds. Adv Funct Mater, 2015, 25: 6733-6743

131 Su Z, Tan JMR, Li X, et al. Cation substitution of solution-processed $\mathrm{Cu}_{2} \mathrm{ZnSnS}_{4}$ thin film solar cell with over 9\% efficiency. Adv Energy Mater, 2015, 5: 1500682

132 Fu J, Tian $\mathrm{Q}$, Zhou Z, et al. Improving the performance of solution-processed $\mathrm{Cu}_{2} \mathrm{ZnSn}(\mathrm{S}, \mathrm{Se})_{4}$ photovoltaic materials by $\mathrm{Cd}^{2+}$ substitution. Chem Mater, 2016, 28: 5821-5828

133 Sun K, Yan C, Huang J, et al. Minority lifetime and efficiency improvement for CZTS solar cells via Cd ion soaking and post treatment. J Alloys Compd, 2018, 750: 328-332

134 Yan Q, Cheng S, Yu X, et al. Mechanism of current shunting in flexible $\mathrm{Cu}_{2} \mathrm{Zn}_{1-x} \mathrm{Cd}_{x} \mathrm{Sn}(\mathrm{S}, \mathrm{Se})_{4}$ solar cells. Sol RRL, 2020, 4: 1900410

135 Neuschitzer M, Rodriguez ME, Guc M, et al. Revealing the beneficial effects of Ge doping on $\mathrm{Cu}_{2} \mathrm{ZnSnSe}_{4}$ thin film solar cells. J Mater Chem A, 2018, 6: 11759-11772

136 Salomé PMP, Rodriguez-Alvarez H, Sadewasser S. Incorporation of alkali metals in chalcogenide solar cells. Sol Energy Mater and Sol Cells, 2015, 143: 9-20

137 Zhou H, Song TB, Hsu WC, et al. Rational defect passivation of $\mathrm{Cu}_{2} \mathrm{ZnSn}(\mathrm{S}, \mathrm{Se})_{4}$ photovoltaics with solution-processed $\mathrm{Cu}_{2} \mathrm{ZnSnS}_{4}: \mathrm{Na}$ nanocrystals. J Am Chem Soc, 2013, 135: 1599816001

138 Yang Y, Kang X, Huang L, et al. Facile and low-cost sodiumdoping method for high-efficiency $\mathrm{Cu}_{2} \mathrm{ZnSnSe}_{4}$ thin film solar cells. J Phys Chem C, 2015, 119: 22797-22802

139 Li JV, Kuciauskas D, Young MR, et al. Effects of sodium incorporation in co-evaporated $\mathrm{Cu}_{2} \mathrm{ZnSnSe}_{4}$ thin-film solar cells. Appl Phys Lett, 2013, 102: 163905

140 Giraldo S, Jehl Z, Placidi M, et al. Progress and perspectives of thin film kesterite photovoltaic technology: A critical review. Adv Mater, 2019, 31: 1806692

141 Yuan ZK, Chen S, Xie Y, et al. Na-diffusion enhanced p-type conductivity in $\mathrm{Cu}(\mathrm{In}, \mathrm{Ga}) \mathrm{Se}_{2}$ : A new mechanism for efficient doping in semiconductors. Adv Energy Mater, 2016, 6: 1601191

142 Yang $\mathrm{Y}$, Kang $\mathrm{X}$, Huang $\mathrm{L}$, et al. Tuning the band gap of $\mathrm{Cu}_{2} \mathrm{ZnSn}(\mathrm{S}, \mathrm{Se})_{4}$ thin films via lithium alloying. ACS Appl Mater Interfaces, 2016, 8: 5308-5313

143 Becerril-Romero I, Acebo L, Oliva F, et al. CZTSe solar cells 
developed on polymer substrates: Effects of low-temperature processing. Prog Photovolt Res Appl, 2018, 26: 55-68

144 Lvmama, http://www.lvmama.com/comment/3465012

Acknowledgements This work was supported by the National Natural Science Foundation of China (51961165108, 51421002, 51972332 and 51627803).

Author contributions Meng Q conceived the idea and supervised the whole project. Duan B wrote the review with support from Shi J. Li D, Luo $\mathrm{Y}$ and $\mathrm{Wu} \mathrm{H}$ contributed to the discussions.

Conflict of interest The authors declare that they have no conflict of interest.

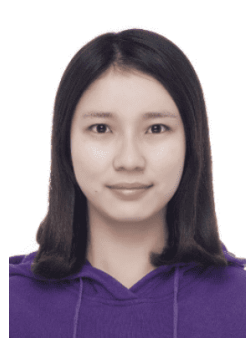

Biwen Duan received her bachelor degree from the School of Chemistry and Chemical Engineering, Huazhong University of Science and Technology in 2016. She is now a $\mathrm{PhD}$ candidate at the Institute of Physics, Chinese Academy of Sciences (CAS) under the supervision of Prof. Qingbo Meng. Her work mainly focuses on developing highly efficient kesterite solar cells and related materials.

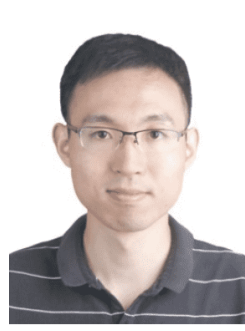

Jiangjian Shi obtained his $\mathrm{PhD}$ degree from the Institute of Physics, CAS in 2017. Now, he is an associate professor at the Institute of Physics, CAS. His research interest includes investigation on charge carrier dynamics, interfacial charge transfer and surface modification in new-generation solar cells.

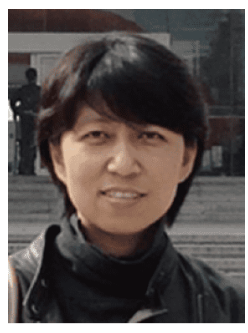

Dongmei Li is currently a professor at the Key Laboratory for Renewable Energy, Institute of Physics, CAS. She received her PhD degree from Jilin University in 1999. She worked as a postdoc in Nihon University and a research assistant in Cardiff University. Her current research interest focuses on solar energy materials \& devices, including new-generation solar cells such as kesterite solar cells and perovskite solar cells, and photocatalysis.

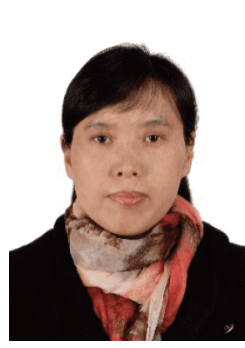

Yanhong Luo is now a professor at the Institute of Physics, CAS. She obtained her $\mathrm{PhD}$ degree from the Institute of Chemistry, CAS in 2003, followed by working as a postdoctoral fellow at the National Institute for Materials Science, Japan. Her research interest includes kesterite solar cells and perovskite solar cells.

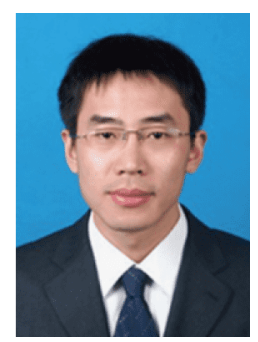

Huijue Wu is currently an associate professor at the Key Laboratory for Renewable Energy, Institute of Physics, CAS. He received his $\mathrm{PhD}$ from the Technical Institute of Physics and Chemistry, CAS in 2011. His research interest focuses on new-generation solar cells including kesterite solar cells and perovskite solar cells.

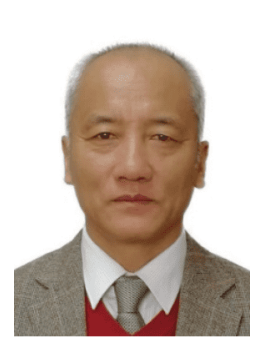

Qingbo Meng is now a professor at the Institute of Physics, CAS. He received $\mathrm{PhD}$ from Changchun Institute of Applied Chemistry, CAS in 1997. He was selected as "Hundreds of Talents" of CAS in 2001, awarded National Science Fund for Distinguished Young Scholars in 2007, and selected as 100 leading talent for "Science and Technology Beijing" in 2013. His current research focuses on solar energy materials and technologies, as well as the research of the dynamics of electron injection, diffusion, recombination in solar cells.

\section{基于原子无序和深缺陷态分析铜锌锡硫硒太阳能 电池效率损失的机理}

段碧雯 ${ }^{1,3}$, 石将建 ${ }^{1}$, 李冬梅 ${ }^{1,3,4}$, 罗艳红 ${ }^{1,3,4}$, 吴会觉 ${ }^{1}$, 孟庆波 ${ }^{1,2,4^{*}}$

摘要 铜锌锡硫硒(CZTSSe) 是具有前景的薄膜光伏材料, 但目前其 太阳能电池的效率仍受限于较大的开路电压损失. 近年来, 研究者 们对CZTSSe太阳能电池效率损失的机理进行了一系列研究, 但尚 未有令人信服的结论. 本综述对有关CZTSSe太阳能电池效率损失 的潜在机理的研究结果进行了系统的总结和分析. 讨论了CZTSSe 材料中原子无序和深能级缺陷态的特征及其对器件性能的影响. 提出了协同效应以辅助理解吸收层中缺陷态相关的电荷损失. 此 外, 总结了缺陷态识别和调控的实验方法, 并试图找到可导致 CZTSSe中极短的少子寿命的关键缺陷态. 通过全面和辩证地理解 CZTSSe太阳能电池的缺陷特性, 我们相信在研究人员的不懈努力 下电池效率将很快有新的突破. 